ISSN: 1641-4713; e-ISSN: 2081-1160

DOI: https://doi.org/10.36551/2081-1160.2019.24.153-188

\title{
Modelo de agronegocios y procesos de acaparamiento de tierra y agua en los oasis de Mendoza, Argentina ${ }^{1}$
}

\author{
Model of Agribusiness and Land-Water Grabbing in the Oases \\ of Mendoza, Argentina
}

Robin Larsimont

Instituto de Ciencias Humanas, Sociales y Ambientales (INCIHUSA)

National Scientific and Technical Research Council (CONICET)

Departamento de Geografía de la Universidad de Buenos Aires (UBA)

ID ORCID: https://orcid.org/0000-0001-8095-1399

E-mail: rlarsimont@mendoza-conicet.gob.ar

Recepción: 17.12.2018

Aprobación: 10.11.2019

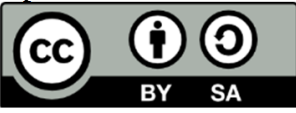

Resumen: Los márgenes de los oasis de la provincia de Mendoza adquirieron estas últimas décadas especial relevancia como focos de inversiones del modelo de agronegocios. Éste se destacó como el protagonista de una verdadera conquista en zonas periféricas de los oasis, expandiendo la frontera agrícola en base la adquisición de terrenos seleccionados por sus características edáficas, la explotación de aguas subterráneas y la aplicación de modernos sistemas de riego. Protagonizada por la llamada nueva vitivinicultura -caracterizada por la producción de vinos de alta calidad enológica y orientada al mercado internacional- esta dinámica se evidenció también en otros sectores frutícolas u hortícolas.

En este artículo indagamos, desde una mirada vertical y pluridimensional, acerca de los procesos que rigen el control sobre determinados espacios rurales y sus recursos hídricos por parte de organizaciones empresariales, ubicadas en los márgenes del oasis del Valle de Uco. Argumentamos que una singular lógica de producción-consumo subyace en estos procesos de acaparamiento. Por un lado, defendemos que esta lógica opera en varias prácticas de agricultura de precisión y buscaremos dar cuenta de la relación que se establece entre los acaparamientos de tierras periféricas con fines agro-productivos, la implementación de tecnologías para irrigarlas y ponerlas en producción, y los

\footnotetext{
${ }^{1}$ Agradecemos el programa TrAndes Postdoctoral Writing Scholarship, mediante el cual se ha realizado la versión final de este trabajo.
} 
mercados de destino. Nos centraremos más específicamente sobre proyectos vitivinícolas y paperos agroindustriales. Por otro lado, defendemos que esta lógica opera también en relación a la creciente conversión de nuevos espacios rurales productivos en enclaves de consumo turístico e inmobiliario, relacionados a la vitivinicultura.

Palabras clave: agua, tierra, irrigación, agronegocios, Mendoza.

\begin{abstract}
The margins of the oases of the Mendoza province have acquired in the last two decades special relevance as a focus of investment of the so-called "agribusiness model." The latter has been the protagonist of a real conquest in peripheral areas of the oasis, expanding the agricultural frontier based on the acquisition of land selected for its edaphic characteristics, the exploitation of groundwater, and the application of modern irrigation systems. Starting with the so-called new vitiviniculture -characterized by the production of high-quality wine destined for export-this dynamic was also evident in other fruit or horticultural sectors.

In this article, from a vertical and multidimensional perspective, we analyze the processes that enable control over certain rural spaces and their water resources by agribusiness corporations located on the margins of the Uco Valley oasis. We argue that a singular logic of production-consumption underlies these grabbing processes. Firstly, we argue that this logic works in several practices of precision agriculture, and we will give an account of the relationship between the expanding of peripheral lands for agro-productive purposes, the implementation of technologies to irrigate and put them into production, and the targeted markets. We will focus more specifically on vitivinicultural projects and agro-industrial potatoes production. Secondly, we argue that this logic also operates in relation to the growing conversion of new productive rural spaces into enclaves of tourist and real estate consumption, related to viticulture.
\end{abstract}

Keywords: water, land, irrigation, agribusiness, Mendoza.

\title{
INTRODUCCIÓN
}

En el actual contexto de valorización de ciertos espacios rurales y de exclusión de otros, los márgenes de los oasis irrigados de la provincia semiárida de Mendoza se presentan como un auténtico "laboratorio" para el debate sobre los procesos de acaparamiento de tierras o land grabbing. Estas tierras anteriormente poco valorizadas, adquirieron estas últimas décadas especial relevancia como focos de inversiones del llamado "Modelo de Agronegocios" (Gras, Hernández, 2013). Éste se destacó como el protagonista de una verdadera conquista en zonas periféricas de los oasis, expandiendo la frontera agrícola en base la adquisición de terrenos seleccionados por sus características edáficas, la disponibilidad de aguas subterráneas y la aplicación de modernos sistemas de riego. Protagonizada por la llamada nueva vitivinicultura -caracterizada por la producción de vinos de alta calidad enológica y orientada al mercado internacional- esta dinámica se evidenció también en otros sectores frutícolas u hortícolas. En el caso de la nueva vitivinicultura esta verdadera conquista de los piedemontes dio lugar a una proliferación de proyectos empresariales que combinaron la actividad de exportación 
con otros ejes de acumulación, como son los complejos agro-turísticos e inmobiliarios de lujo.

En este artículo indagamos acerca de los procesos que rigen el control sobre determinados espacios rurales y sus recursos hídricos por parte de diversas organizaciones empresariales. Nuestras observaciones apuntan a que paralelamente a esta expansión de la frontera agrícola sobre estas tierras secas, se viene conformando una singular lógica de producción-consumo. Defendemos que esta lógica opera sustancialmente en la llamada agricultura de precisión, donde observamos que detrás de las habituales y sutiles narrativas eco-tecnocráticas subyacen procesos de homogeneización de la producción y de estandarización del consumo, de acuerdo a criterios internacionales. En otro registro, argumentamos que este singular esquema de producción-consumo opera también en relación a la creciente conversión de nuevos espacios rurales productivos en enclaves de consumo turístico e inmobiliario -en general de elite-, donde la arquitectura y el paisajismo se presentaron como estrategias de marcas de distinción.

A los fines de encaminar nuestra argumentación nos centraremos sobre el oasis del Valle de Uco, donde la expansión de la frontera agrícola cobró especial relevancia estas últimas dos décadas. En cuanto a las técnicas de análisis, las entrevistas en profundidad y semi-estructuradas, los mapeos mentales, las visitas a campo y la observación participante fueron técnicas privilegiadas para el acceso y la producción de datos cualitativos. Movilizamos asimismo fuentes segundarias -tales como censos, prensa, sitios web e informes comerciales-, con fines más bien descriptivos. Hemos organizado este documento en cuatro bloques.

Primero, desde una mirada netamente teórico-metodológica, nos ceñiremos en considerar el acaparamiento de tierras como una dimensión, entre otras, de lo que llamaremos un modelo de agronegocios. Inspirándonos en el materialismo histórico-geográfico y, en particular, en ciertas advertencias de Henri Lefebvre, proponemos abordar este fenómeno desde una mirada vertical y atenta a las dimensiones materiales, discursivas y simbólicas.

Segundo, sintetizaremos la fuerte fragmentación territorial asociada a la conformación de los oasis en la provincia y sus recientes restructuraciones productivas. Estas precisiones histórico-geográficas son necesarias para destacar la inercia de ciertas relaciones de poder en torno al manejo del agua en la provincia, frecuentes también en la agricultura de oasis en otras zonas áridas de América Latina (Lavie, Marshall, 2017; Oré, Muñoz, 2018; Damonte, Boelens, 2019).

Tercero, y con esta contextualización como telón de fondo, analizaremos en profundidad los procesos de conquista de los piedemontes en este oasis del Valle 
de Uco. Nos centraremos, por un lado, sobre la agricultura de precisión con especial hincapié en las estrategias de localización y conformación de nuevas áreas productivas relacionadas a la vitivinicultura y a la producción de papas destinadas a los fast-food. Haremos ahí especial insistencia en la relación que se establece entre estos acaparamientos de tierras, la implementación de tecnologías para irrigarlas y ponerlas en producción, y los mercados de destino. Por otro lado, en relación a proyectos vitivinícolas con actividades turísticas y/o inmobiliarias complementarias buscaremos desentrañar la contradicción que se presenta entre la pesquisa de criterios de singularidad ante las expectativas de los consumidores o visitantes y la banalización de la experiencia.

Cuarto, y a la luz de esta dinámica expansiva y de sus protagonistas, describiremos lo que llamamos la ideología de la expansión. Mostraremos que al configurarse como justificativo de la conquista de los piedemontes contribuye a encubrir las realidades socio-ambientales sobre las cuales se despliegan estos acaparamientos de tierra.

\section{MODELO DE AGRONEGOCIO Y ACAPARAMIENTOS DE TIERRAS, UNA MIRADA VERTICAL Y PLURIDIMENSIONAL}

En el actual escenario neoliberal, las formas de gestión de determinadas organizaciones empresariales contemplan cada vez más a escala mundial sus estrategias de abastecimiento de nuevos mercados y de acceso a factores de producción más baratos (Delgado Cabeza, 2010). Por consiguiente, los procesos de producción, distribución y consumo de la llamada triada global alimento-forrajecombustible (Gorenstein, Ortiz, 2016; Franco, Mehta, Veldwisch, 2013) se encuentran cada vez más integrados por encima de las fronteras estatales. En este contexto, se multiplicaron estos últimos años estudios sobre los procesos de acaparamiento de tierras o land grabbing, siendo América Latina un ámbito de análisis recurrente (Borras, Franco, Gómez, Kay, Spoor, 2012; Borras, Kay, Gómez, Wilkinson, 2012; Bernardes, Maldonado, 2017). A su vez, simultáneamente a la proliferación de estudios académicos se conformaron grupos de investigaciones enfocados sobre este fenómeno desde organizaciones internacionales de diferentes índoles como la FAO, OXFAM, GRAIN o LAND MATRIX. Dentro del amplio abanico de estudios sobre el tema, varios de ellos enmarcan estas dinámicas rurales en el proceso de globalización del sistema agroalimentario, en particular en sus manifestaciones más recientes (McMichael, 2012; Delgado Cabeza, 2010; Franco et al., 2013). En esta trama, el land grabbing suele estar estrechamente 
vinculado al proceso de expansión de la frontera agrícola (Bernardes, Maldonado, 2017; White, Borras, Hall, Scoones, Wolford, 2012); o sea, a la "incorporación de una importante cantidad de tierras al sistema de producción agrícola, conquistando espacios anteriormente desvalorizados (llamados 'improductivos') u ocupados por la cría de animales" (Gras, Hernández, 2009: 25). Ahora bien, con el fin de no restringirnos a dinámicas sectoriales agro-alimentarias, enmarcamos nuestra propuesta en una línea de estudios que subraya el carácter multifacético de las lógicas de acaparamiento de tierras (Margulis, McKeon, Borras, 2014; Zoomers, 2010). Dicho de otra manera, queremos abordar las lógicas que rigen este fenómeno de land grabbing al mirar más allá de la compra de tierra, preguntándonos tanto por lo que apalanca esta adquisición como por el destino hacia el cual apuntan sus productos.

Por consiguiente, en este trabajo, consideraremos el acaparamiento de tierras (A) como una dimensión, entre otras, de un modelo de agronegocios ${ }^{2}$ (MA); o sea, de una lógica de acumulación flexible centrada en la producción, transformación, distribución y consumo de productos agropecuarios. Para entender este supuesto general es menester destacar otras cuatro dimensiones claves e interconectadas, y que comparten gran parte de las organizaciones empresariales que operan dentro de este modelo de agronegocios (Imagen 1).

1. Estas organizaciones empresariales suelen depender de una flexibilización del acceso tanto a los factores productivos (tierra-agua, capital, trabajo) como a los mercados. Un contexto económico desregulado (D) les permite, por lo tanto, desplegar sus estrategias empresariales, conectando nuevos espacios productivos a nuevos espacios de consumo (McMichael, 2012; Delgado Cabeza, 2010; Van der Ploeg, 2008).

2. Esta desregulación tiende a facilitar fuertes oleadas de financiación $(\mathbf{F})$ depredadoras, que convierten al sector agropecuario en espacio de especulación (Gras, Hernández, 2009). Por lo tanto, mientras la valorización e incursión financiera -que toma varias formas- somete el sistema productivo a lógicas extra-agrarias, puede conformarse también como un factor de flexibilidad en las estrategias de relocalización empresariales.

3. La continua búsqueda de mayor velocidad de rotación del capital induce una inflexión en los procesos productivos y de gestión mediante experticias tanto agronómicas como de gestión empresarial (Gras, Hernández, 2009).

\footnotetext{
${ }^{2}$ Nos inspiramos claramente en esta definición de los trabajos de Carla Gras y Julia Hernández (2013), particularmente de la idea de modos de apropiación diferencial de sus distintos componentes (ver también Chazarreta, 2019).
} 
Defendemos por lo tanto que esta doble pericia, dependiente de una perpetua innovación agronómica y en comunicación (Atkins, Bowler, 2001) opera en el marco de un medio técnico-científico-informacional ${ }^{3}$ (T-C-I), conformándose como verdadero paradigma para estas organizaciones empresariales.

4. Una compleja relación producción-consumo (P-C) caracteriza las estrategias empresariales que operan en este modelo de agronegocios. Retomando en cierta medida la idea que "la producción crea el consumidor" y el "modo de consumo" (Marx, 1963 [1859]: 343) entendemos que más allá de la elaboración de mercancías agropecuarias las organizaciones empresariales tienen que trabajar también la forma de consumirlas. Por lo tanto, prestaremos atención a ciertas estrategias de marketing -territorial y empresarial-, ya que al promover una continua búsqueda de marcas de distinción y de singularidad, se presentan como herramientas indispensables para garantizar y fidelizar el destino de los diversos productos (Harvey, 2007).

\section{IMAGEN 1: EL MODELO DE AGRONEGOCIOS (MA) Y SUS PRINCIPALES COMPONENTES}

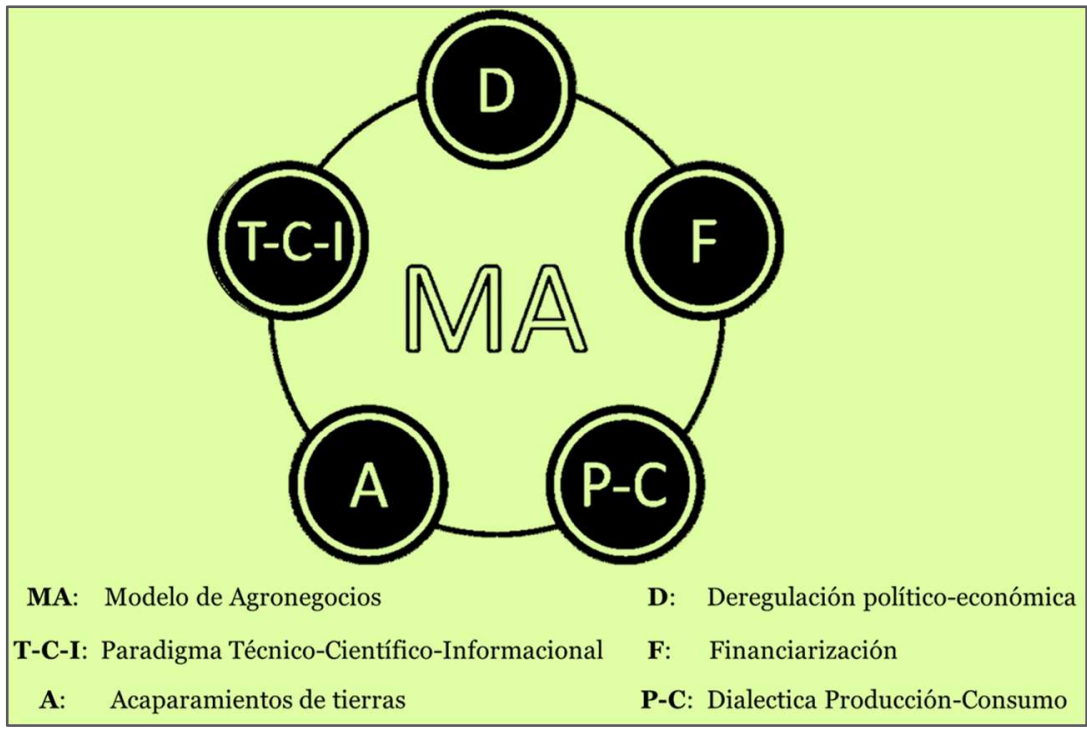

Fuente: elaboración propia.

\footnotetext{
${ }^{3}$ Según el geógrafo Milton Santos en este medio, la ciencia y la tecnología, conjuntamente con la información, están en la propia base de la producción, de la utilización y del funcionamiento del espacio (2000).
} 
Ahora bien, cabe subrayar que a la luz de los anteriores planteamientos resaltamos dos vigilancias epistemológicas a la hora de entender los procesos de acaparamientos de tierra en una área semiárida como la provincia de Mendoza.

En primer lugar, abogamos por la necesidad de tener una visión vertical que distingue tres niveles; "[...] el suelo, el subsuelo y el sobresuelo" (Lefebvre, 2014: 360). En este esquema, "la tierra no es solo la agricultura, [sino] también el subsuelo y sus recursos" (Lefebvre, 2014: 360). Así, y en sintonía con esta visión, consideramos la lógica de acaparamiento de tierras como "acciones de captación del control sobre extensiones de suelo y otros recursos" (Borras, Franco et al., 2012). Desde esta mirada vertical sobre la valorización capitalista de la tierra dirigiremos nuestra atención sobre sus características edáficas, agro-climáticas e incluso paisajísticas, pero haremos especial hincapié en el control de las aguas subterráneas (Hoogesteger, Wester, 2015). En este sentido, para caracterizar la problemática del uso del agua que suponen ciertos acaparamientos de tierras nos remetimos a lo que se ha denominado como el water o blue grabbing (Mehta, Veldwisch, Franco, 2012; Allan, Keulertz, Sojamo, Warner, 2013). Lo entendemos más específicamente como "la captación del control no sólo del agua en sí, sino también de la capacidad de decidir cómo se utilizará, por quién, cuándo, durante cuánto tiempo y para qué fines [...]”. (Franco et al., 2013).

En segundo lugar, consideramos que estos tres niveles una vez "integrados" en nuestro caso por mediación del modelo de agronegocios "se afirman como elementos o funciones específicas de la expansión capitalista" (Lefebvre, 2014: 360). Así, para caracterizar las múltiples formas a través de las cuales estos tres niveles se internalizan en la circulación y acumulación de capital, resulta oportuno referirnos a la tesis de una producción de naturaleza (Smith, 1984). Dicho de otra manera $-\mathrm{y}$ con esto introducimos nuestra segunda vigilancia epistemológica-, esta producción de naturaleza que subyace a los procesos de acaparamientos, no sólo se tiene que entender en un registro técnico-material sino también discursivo y simbólico. A modo de ejemplo concordamos totalmente con White et al. cuando afirman que

La justificación de las inversiones en tierras a gran escala se presenta a menudo en torno a una serie de "narrativas de crisis", vinculadas a una escasez creciente y a una catástrofe inminente" [y] que la solución a estas "crisis" alimentarias, energéticas y climáticas consiste en captar el potencial de las llamadas "tierras marginales, vacías y disponibles" en todo el mundo (White et al., 2012). 
Más concretamente, en nuestro trabajo prestaremos especial atención por un lado a ciertas formaciones discursivas regionales ${ }^{4}$ en torno a la necesidad de "conquistar el desierto" y a las cuales se acoplan las estrategias de marketing empresarial. Y, por otro lado, a ciertas formaciones discursivas eco-tecnocráticas relativas a nuevos imperativos e instrumentos de la eficiencia ambiental ${ }^{5}$.

\section{LOS OASIS, ISLAS VERDES EN TIERRAS DE ARENAS}

La provincia de Mendoza se ubica en el centro oeste de la Argentina, en la llamada diagonal árida de América Latina. El clima resultante se caracteriza por una marcada sequedad y unos máximos pluviométricos que difícilmente superan los 200 milímetros anuales en la mayor parte de la circunscripción provincial y con distribución irregular. Esto ha incentivado que la agricultura sólo sea posible mediante sistemas de riego artificial. De esta forma, los aportes hídricos que se utilizan en estas tierras secas irrigadas, -es decir, en los llamados oasis-, provienen casi en su totalidad de la desviación de los ríos de régimen glacial que bajan de la Cordillera de los Andes y de ciertas cuencas hidrogeológicas.

A lo largo de la historia, la desviación de estos ríos ha configurado una fuerte fragmentación territorial (Mapa 1). El patrón resultante se caracteriza por la presencia de oasis artificiales de riego ${ }^{6}$, "islas verdes" en medio de vastos espacios desérticos no irrigados y relativamente despoblados, calificados de "espacios invisibles" (Montaña, 2012: 113). La díada "civilización o barbarie”, que respaldó las sucesivas Campañas del Desierto al final del siglo XIX, parece haber operado en la conformación de este patrón desigual mediante la exclusión de campesinos y comunidades indígenas, arrinconados en tierras marginales, relegados a la producción ganadera de subsistencia u obligados a ser peones en las grandes estancias. Los oasis, al contrario, caracterizados por una densa red de distribución superficial de agua, reflejan la identidad "visible" e hegemónica de la provincia. Esta identidad "se apoya en los relatos de la gran gesta en la cual los mendocinos

\footnotetext{
${ }^{4}$ Las formaciones discursivas regionales se refieren a ciertos "ciertos modos de pensamiento, lógicas, temas, estilos de expresión y metáforas típicas de la historia discursiva de una región" (Peet, Watts, 1996: 16).

${ }^{5} \mathrm{Al}$ respecto el concepto de "acaparamiento verde" (o green grabbing) remite a procesos de apropiación de terrenos que se justifican en el supuesto cuidado del medioambiente o más precisamente por su interés desde el punto de vista de la biodiversidad (Fairhead, Leach, Scoones, 2012).

${ }^{6}$ Los cuales concentran sobre apenas $5 \%$ de la superficie provincial, la gran mayoría de la población, repartida en los principales centros urbanos y zonas agroindustriales. En la provincia podemos destacar tres principales oasis (1) Norte (2) Centro o Valle del Uco, (3) Sur, y un otro secundario, el oasis de Malargüe.
} 
se reconocen como unidos y exitosos: la lucha contra el desierto y la construcción del oasis" (Montaña, 2013: 107). Ahora bien, si los protagonistas de esta historia son "el domador del agua" y "el labriego tesonero" el pilar en torno al cual sigue girando gran parte de la vida política, social y cultural de la provincia lo constituye la emblemática agroindustria vitivinícola (Montaña, 2012; Martín, 2010).

MAPA 1. SitUACIÓN DE LA PROVINCIA Y SUS TRES PRINCIPALES OASIS.

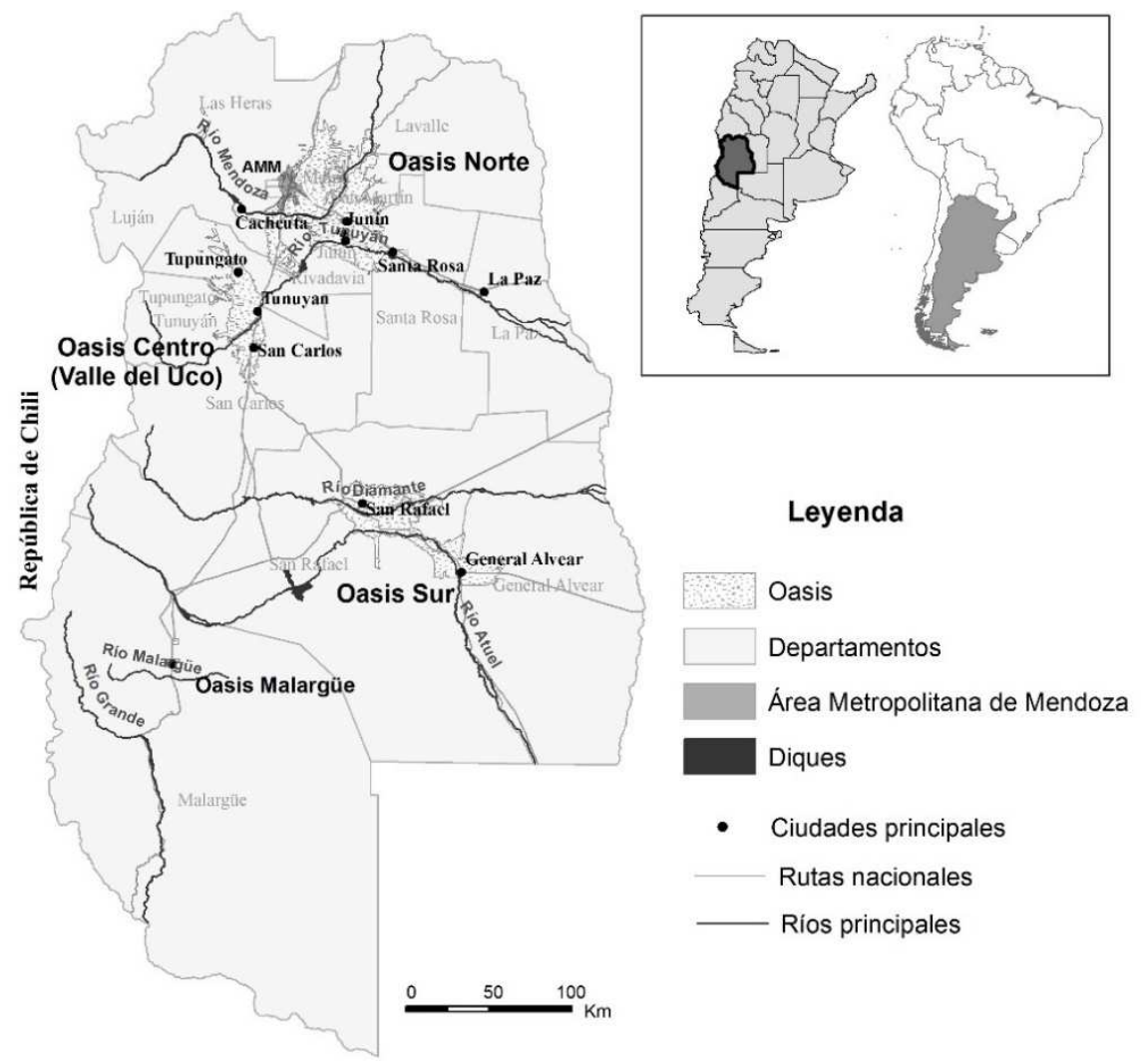

Fuente: elaboración propia.

La concentración de la propiedad y la distribución desigual de los derechos de riego dentro de los oasis fueron procesos muy prematuros en la región. Sin embargo, el proyecto político de reconversión productiva al final del siglo XIX hacia la vitivinicultura y la misión hidráulica que implicó, consolidaron una "apropiación gubernamentalizada" del agua y de la tierra; es decir, una "rápida y rígida- estructuración social a través del "gobierno del agua" por parte de las 
clases dominantes locales" (Martin, 2010: 55). Asimismo, el orden jurídico de las aguas, que favorecía la expansión de los oasis según los intereses de la oligarquía local, se consolidó con la sanción de la Ley de Aguas de 1884. El ámbito de aplicación de dicha Ley, todavía vigente, sigue descansando sobre las autoridades del Departamento General de Irrigación -en adelante DGI-, responsable de la administración y distribución del recurso en todos los oasis. Conformándose como verdaderas hidrocracias (Molle, Mollinga, Wester, 2009), el DGI, junto con las Inspecciones de Cauces ${ }^{7}$, administran la densa red de distribución superficial de agua para riego, un estructurador clave de estos oasis ${ }^{8}$. Al principio de la década del 1970 se le adjudicó también al DGI el cargo de administrar el aprovechamiento general de las aguas subterráneas, que han ganado en consideración con la sanción de las leyes 4035 y 4036. Estas leyes surgieron como respuesta a una intensificación del bombeo al final de la década anterior en el contexto de una fuerte sequía y de la necesidad para productores capitalizados de recurrir al agua subterránea como fuente complementaria ${ }^{9}$. Esta gestión expansionista del agua estaba al servicio de lo que se conoce localmente como el "modelo centenario vitivinícola" (Mateu, 2007); a saber, una especialización productiva regional centrada "en la producción de grandes volúmenes de 'uvas comunes' y 'vinos de mesa', orientados casi exclusivamente al mercado interno" (Altschuler, Collado, 2013). Este modelo socio-productivo que se extendió en cierta medida a otros sectores frutícolas y hortícolas dio lugar al desarrollo de una importante clase media rural y permitió en gran parte del siglo XX una cierta independencia político-económica frente al modelo pampeano. Ahora bien, este modelo empezó a mostrar francos signos de agotamiento a partir de 1980 (Altschuler, Collado, 2013; Altschuler, 2012; Chazzareta, 2013).

Las medidas de desregulación y de apertura de la economía argentina, con mayor expresión en la década siguiente, en concordancia también con otros factores de orden tecnológico y organizacional, convirtieron a los oasis en el escenario de importantes procesos de reestructuraciones productivas. En un discurso

\footnotetext{
${ }^{7}$ Son personas jurídicas públicas que se conforman como las autoridades de las unidades mínimas de manejo del agua superficial a nivel local. Son elegidas por los regantes de cada inspección por votación directa, pero ponderada por la cantidad de hectáreas que cada regante tiene empadronado. ${ }^{8}$ En esta red, el río, puede ser regulado por un embalse y/o un Dique Derivador. Este dique deriva el agua por un canal principal o canal matriz que se subdivide en otros secundarios; a saber, las redes de distribución, con un trazado de cauces menores llamados ramas o hijuelas y que son las que llevan el agua a la propiedad

${ }^{9}$ Paralelamente, ciertas políticas fomentaban la incorporación de zonas áridas a la actividad agropecuaria mediante el uso de aguas subterráneas, facilitando la financiación de las inversiones necesarias con desgravaciones impositivas.
} 
del año 1995, el presidente del Instituto Nacional de Vino (INV) reclamaba un "drástico ajuste y transformación de los sectores que hoy no tienen lugar en la nueva economía" (Vinífera, 1996: 40). Evidenciando la violencia epistémica que permeaba la atmósfera neoliberal de la década de los 90, precisaba en su presentación que "ese ajuste lo hará el mercado en forma cruel y traumática para quienes se nieguen a aceptar la realidad" (Vinífera, 1996: 40). A ese respecto, y en referencia al agro expoliado y empobrecido que quedó luego de la ofensiva de esas nuevas fuerzas socioeconómicas neoliberales, nos referiremos al concepto fuerte de "restos del naufragio" (Ratier, 2013). En el sector de la vitivinicultura, mientras solo las grandes bodegas tradicionales más capitalizadas pudieron enfrentar esta reconversión ${ }^{10}$, muchas otras desaparecieron, por quiebra o fueron compradas por inversores foráneos.

Paralela y progresivamente, se consolidaba el "modelo de la calidad ${ }^{11 "}$ (Altschuler, Collado, 2013; Chazaretta 2019), también conocido como nueva vitivinicultura (Montaña, 2012). Caracterizada por importantes cambios técnicos y organizacionales, esta nueva vitivinicultura apunta a la producción de vinos de alta calidad y alto precio destinados principalmente a mercados internacionales. A su vez, otro de sus rasgos más destacados ha sido contribuir a la proliferación de proyectos empresariales que combinaron la actividad vitivinícola de exportación con otros ejes de acumulación, como son los complejos agroturísticos e inmobiliarios de lujo (Larsimont, 2016; Torres, Pastor, Grosso, Scoones, 2018). Por otra parte, el proceso de concentración se dio también en otros sectores frutícolas y hortícolas (Carballo, 2019), donde aparecieron focos atractivos para el capital corporativo y su estrategia de penetración de mercados de masas tales como el de la alimentación de alta gama.

Sintetizando, podemos decir que los procesos de reestructuraciones productivas constituyeron un verdadero arreglo espacio-temporal selectivo, en el sentido de que la distribución de sus beneficios resultó fuertemente desigual en términos socio-espaciales (Harvey, 2007). La tabla siguiente, además de evidenciar cierta inercia de la crisis - particularmente en el periodo 1988-2002- da cuenta de la inequidad espacial resultante de dicha reestructuración a nivel provincial (Tabla 1). Si comparamos los datos censales de 1988 y 2002, observamos un

\footnotetext{
${ }^{10}$ Efectivamente, como bien recuerda Adriana Chazarreta (2013), la reconversión "no solo implicó la entrada de nuevos capitales portadores de nuevas lógicas de producción y la salida de antiguos capitales sino también un movimiento muchas veces ignorado: el de la persistencia".

${ }^{11}$ Más allá de sus antagonismos, como precisan las autoras, estos dos modelos coexisten en tensión e interrelación (Altschuler, Collado, 2013).
} 
descenso general de la superficie implantada en los tres principales oasis. Sin embargo, es de menor intensidad en el oasis centro (Valle de Uco). Ahora bien, si comparamos los datos del censo de 2002 y aquellos del Registro del Uso de la Tierra (RUT) para el año $2014^{12}$, observamos que los oasis retoman un crecimiento, particularmente el oasis norte y centro.

TABLA 1. HECTÁREAS CULTIVADAS EN LOS DISTINTOS OASIS.

\begin{tabular}{|c|c|c|c|c|c|c|c|c|}
\hline Oasis & $\begin{array}{c}\text { CNA } \\
\mathbf{1 9 8 8} \\
\text { (ha) }\end{array}$ & $\begin{array}{c}\text { CNA } \\
\mathbf{2 0 0 2} \\
\text { (ha) }\end{array}$ & $\begin{array}{c}\text { RUT } \\
\mathbf{2 0 1 4} \\
\text { (ha) }\end{array}$ & $\begin{array}{c}\text { Diferencia } \\
\mathbf{2 0 0 2 - 8 8} \\
\text { (ha) }\end{array}$ & $\begin{array}{c}\text { Var } \\
\mathbf{2 0 0 2 - 8 8} \\
\mathbf{( \% )}\end{array}$ & $\begin{array}{c}\text { Diferencia } \\
\mathbf{2 0 1 4 - 2 0 0 2} \\
\text { (ha) }\end{array}$ & $\begin{array}{c}\text { Var } \\
\mathbf{2 0 1 4 - 2 0 0 2} \\
\text { (\%) }\end{array}$ & $\begin{array}{c}\text { Var } \\
\mathbf{2 0 1 4 - 8 8} \\
\text { (\%) }\end{array}$ \\
\hline $\begin{array}{c}\text { Oasis Norte (Cuenca } \\
\begin{array}{c}\text { Mendoza-Tunuyán } \\
\text { Inferior) }\end{array}\end{array}$ & 165511 & 149804 & 188451 & -15707 & $-9,5$ & 38647 & 25,8 & 13,9 \\
\hline $\begin{array}{c}\text { Oasis Centro-Valle } \\
\text { de Uco (Cuenca } \\
\text { Tunuyán Superior) }\end{array}$ & 51367,9 & 48303 & 57045 & $-3064,9$ & $-6,0$ & 8742 & 18,1 & 11,1 \\
\hline $\begin{array}{c}\text { Oasis Sur (Cuenca } \\
\text { Atuel y Diamante) }\end{array}$ & 73694,1 & 66457 & 71513 & $-7237,1$ & $-9,8$ & 5056 & 7,6 & -3 \\
\hline Total & 290573 & 264564 & 317009 & -26009 & $-25,3$ & 52445 & 19,8 & 9,1 \\
\hline
\end{tabular}

Fuente: elaboración propia en base a Censo Nacional Agropecuario (CNA) 1988 y 2002 (DEIEINDEC, s.f.) y Registro de Uso de la Tierra (RUT) 2014 (DACC, s.f.).

La intensidad de las transformaciones acontecidas estas tres últimas décadas en el oasis centro -en adelante Valle de Uco- merece una atención especial. Este oasis que hasta finales de los años 1980 conformaba todavía un área esencialmente hortofrutícola de pequeños y medianos productores, pasó a consolidarse en tiempos de la globalización del sistema agroalimentario como un nuevo Napa Valley $^{13}$ latinoamericano. Este apodo remite esencialmente a su rápida reconversión hacia la nueva vitivinicultura, ya que predominaron en esta reconversión las uvas de alta calidad ${ }^{14}$. Este giro resultó bastante decisivo, como se puede apreciar en el gráfico siguiente, aunque también se puede observar una leve recuperación de las superficies frutícolas y hortícolas a partir del 2008 (Gráfico 1).

\footnotetext{
${ }^{12}$ El Registro de Uso de la Tierra (RUT) consiste en un registro provincial creado por la ley 4438. Es de carácter obligatorio para todos los establecimientos agropecuarios existentes en el territorio provincial. En dicho registro constan el número de productores, los establecimientos, la extensión en hectáreas y el uso del suelo. Surge también como voluntad de actualizar los datos censales desde el último censo agropecuario disponible de 2008, el cual presentó varias irregularidades. Aunque la comparabilidad entre ambos datos evidencia ciertos desfases, el RUT es la principal fuente estadística actualizada -hasta finales de 2014- referida a la superficie y al uso agrícola en general a escala provincial.

${ }^{13}$ En referencia al valle californiano, ícono del modelo de agronegocios vitivinícolas a nivel mundial.

${ }^{14}$ Efectivamente, la marca de identidad del perfil vitivinícola del Valle de Uco se tiene que buscar en su orientación hacia la calidad y la exportación. Por ejemplo, para el año 2016, el Valle de Uco comercializó un total de $481.051 \mathrm{hl}$ de vinos, de los cuales el $77 \%$ se exportó hacia mercados externos, correspondiendo a una producción de alta calidad - al 93\% varietales- (INV, 2017).
} 
GRÁFICO 1. EVOLUCIÓN SUPERFICIES EN VALLE DE UCO POR CULTIVOS 1988-2014 (OTROS CULTIVOS $=$ FORESTALES Y FORRAJEROS).

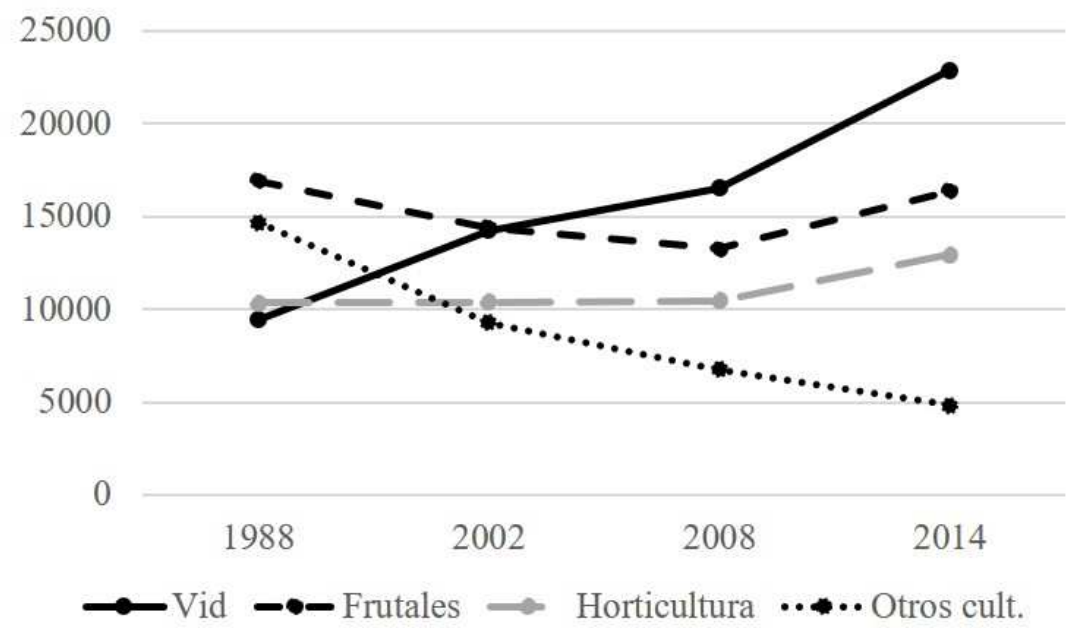

Fuente: elaboración propia en base a DEIE-INDEC, CNA 1988-2002 y RUT 2014 (DACC, s.f.).

Ahora bien, con la inserción de diversos capitales del sector o extra-agrarios, nacionales y cada vez más extranjeros, el proceso de restructuración del complejo agro-productivo mendocino dio lugar a una singular dinámica territorial. Nos referimos al desplazamiento de la frontera agrícola hacia los márgenes de los oasis en base al uso casi exclusivo de aguas subterráneas. Así, tierras ubicadas en los márgenes cercanos de los oasis y anteriormente poco valorizadas por su localización fuera de la red superficial de distribución de agua de riego, se vieron cada vez más cotizadas por organizaciones empresariales fuertemente capitalizadas e integradas en circuitos agroalimentarios globales. Si bien la tendencia hacia una expansión de la frontera agrícola se ha desplegado en los tres principales oasis de la provincia, el caso del Valle de Uco viene cobrando particular relevancia. Por lo tanto, sin perder una visión general de este fenómeno, acotaremos a continuación nuestras observaciones a este oasis.

\section{AGUA SUBTERRÁNEA Y CONQUISTA DE LOS PIEDEMONTES EN EL VALLE DE UCO}

Cabe recordar que la expansión del oasis del Valle de Uco mediante el uso de agua subterránea como fuente complementaria no es un fenómeno nuevo (Roncelli, 1969; Marzo, Inchauspe, 1967). Tal y como se puede apreciar en la tabla que acompaña el mapa siguiente, del total de las 2.557 perforaciones 
registradas en el año 2014, 1.032 pozos -o sea más del 40\%- son anteriores al año 1970 y, aproximadamente, el 80\% anteriores a la década del 1990, tal y como se aprecia en el sector rojo del Mapa 2.

MAPA 2: PRINCIPALES PROYECTOS EMPRESARIALES QUE PROTAGONIZARON LA EXPANSIÓN DE LA FRONTERA AGRÍCOLA EN BASE AL USO DE AGUA SUBTERRÁNEA SEGÚN TIPO DE CULTIVO.

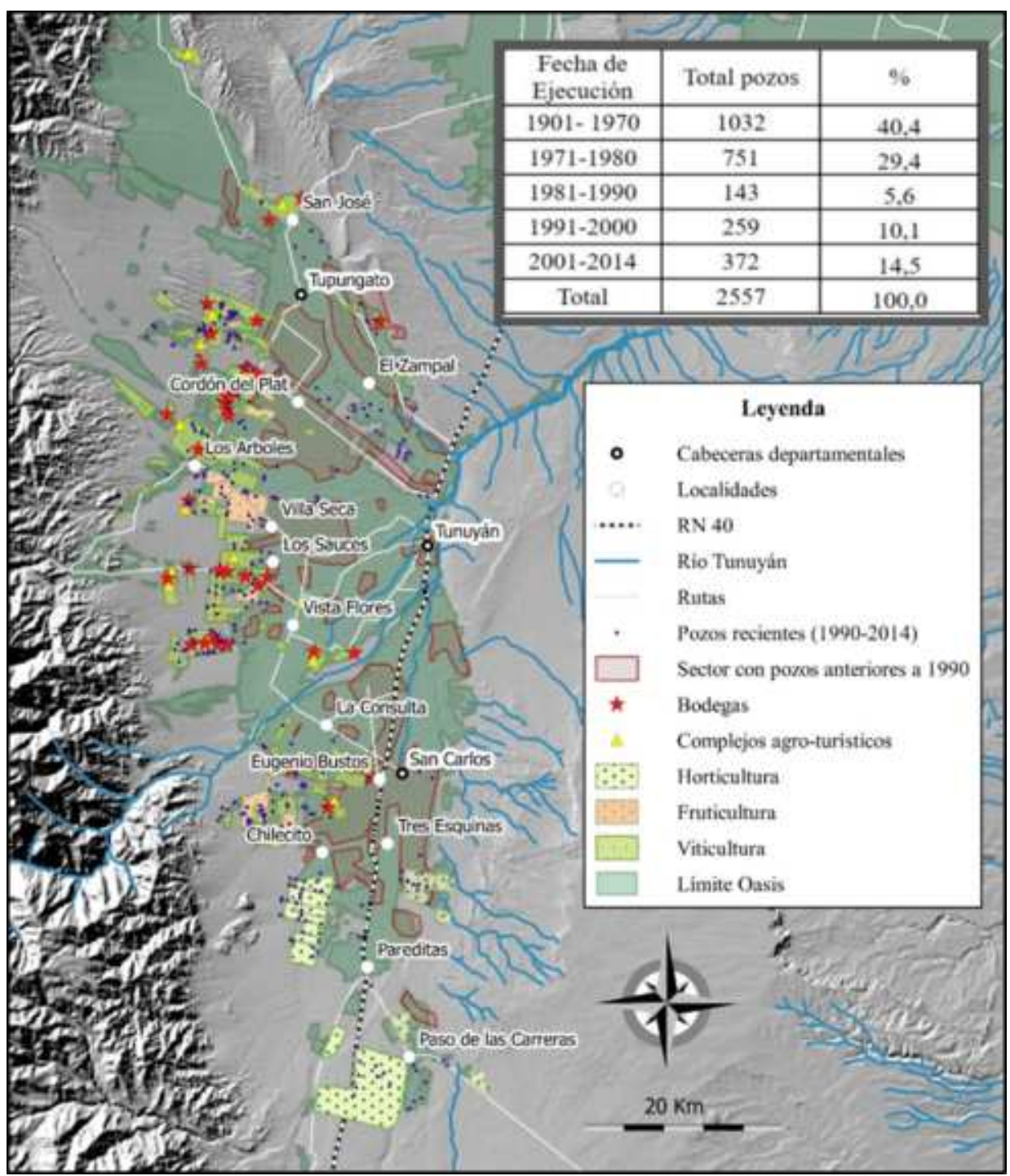

Fuente: elaboración propia en base a información de DGI, s.f. 
Ahora bien, la particularidad de las perforaciones recientes, realizadas entre 1990 y 2014, reside en su ubicación principalmente en la periferia del oasis, en áreas en su mayoría no conectadas a la red de distribución superficial. Efectivamente, en el marco del proceso de restructuración productiva, diversas organizaciones empresariales han encontrado en estos márgenes del Valle de Uco y en la posibilidad de obtener pozos un ámbito ideal para desarrollar nuevos proyectos agro-productivos, diversificando sus inversiones y/o adquiriendo mayor escala. Aunque un mapeo general de cultivos evidenciaría un perfil de tipo mosaico, se han conformado ciertas áreas de producción especializadas, tal y como lo ilustra el mapa.

Podemos observar una importante expansión de la viticultura, principalmente hacia el margen oeste del oasis. Varios proyectos cuentan con bodegas y algunos implementaron actividades inmobiliarias y turísticas como complemento de la actividad vitivinícola. Cabe mencionar también, aunque en menor medida, algunos proyectos frutícolas, básicamente de carozo y nogales. En cuanto a la expansión referida a la horticultura, cabe destacar varios proyectos en la zona sur del oasis, al sur de la ciudad cabecera de San Carlos, de ambos lados de la ruta nacional RN40. Si bien los perfiles socio-económicos de las organizaciones empresariales que lideraron esta conquista de los piedemontes tienen sus particularidades, suelen tener en común un cierto nivel de capitalización y de tecnología, así como cierto grado de integración en circuitos largos de comercialización. Consciente de estas particularidades, lo que nos interesa destacar en este trabajo es más bien el proceso espacial de expansión de la frontera agrícola en base al uso de agua subterránea, lo que llamamos conquista de los piedemontes.

En esta "conquista", la búsqueda de agua subterránea ${ }^{15}$ se volvió inseparable del proceso de selección y compra de la tierra, si bien que podemos hablar de una estrategia de acceso al nexo agua-tierra ${ }^{16}$. A continuación, analizamos cómo se desarrolla esta conquista de los piedemontes: primero en relación a la agricultura de precisión; luego en referencia a las actividades turísticas e inmobiliarias vinculadas a la vitivinicultura.

\footnotetext{
${ }^{15}$ El procedimiento para obtener una concesión de uso de agua subterránea se inicia mediante la presentación de una solicitud pública ante el DGI y su aprobación o rechazo depende de informes y dictámenes técnicos oficiales (Erice, 2013).

${ }^{16}$ Cabe destacar el papel que han tenido ciertos geólogos y, particularmente, hidrogeólogos en este proceso de ubicación. Varios prestaron servicios de prospección al sector privado, directamente por asuntos hídricos, pero también edáficos.
} 


\section{RIEGOS MODERNOS Y AGRICULTURA DE PRECISIÓN}

Si bien el acceso al agua subterránea es un paso decisivo en esta conquista de los piedemontes, este proceso suele ir de la mano con la implementación de lo que se conoce como la agricultura de precisión. La Sociedad Internacional de Agricultura de Precisión la define como

[...] una estrategia de gestión que recopila, procesa y analiza datos temporales, espaciales e individuales y los combina con otra información para apoyar las decisiones de gestión de acuerdo con cierta variabilidad estimada para mejorar la eficiencia en el uso de los recursos, la productividad, la calidad, la rentabilidad y la sostenibilidad de la producción agrícola. (ISPAG, 2019 [traducción propia])

A continuación tratamos de dar cuenta de la relación que se establece entre las estrategias de localización y conformación de nuevas zonas productivas; el uso de aguas subterráneas y la implementación tecnologías de riego; y los mercados de destino. Como punto de partida de nuestra argumentación, partimos de la opinión de un especialista en riego del Instituto Nacional del Agua (INA): "En general, todas las empresas te quieren entregar un producto con una calidad lo más uniforme en el tiempo, porque si no, el cliente se te va, se te va a otra marca" (Entrevistado $\mathrm{N}^{\circ} 1$ ). Siguiendo su razonamiento, los "factores más importantes" para lograr esta homogenización y uniformidad en la producción y a su vez garantizar la fidelización de ciertos consumidores "son los espacios". Añadía al respecto que:

"[...] en los perímetros [del oasis] habían espacios grandes, segundo, uniformes, tercero, no tenían vecinos $[\ldots]$ y después, bueno, en el perímetro era se suponía donde tenía el mejor suelo, porque era suelo virgen" [Además] "si te vas cerca de la montaña esa agua es buena, recién derretida del deshielo, por lo tanto, no está contaminada, el aire es impoluto, o sea esta fantástico" [...] "tenés suelo, agua y aire totalmente vírgenes digamos, sin ningún tipo de contaminación” [...] (Entrevistado $\mathrm{N}^{\circ} 1$ ).

Estas afirmaciones merecen, por supuesto, matices, pero sirven de disparador para repensar la relación que se establece entre las estrategias de localización, las prácticas productivas y el destino de los productos. Cabe recordar, sin embargo, que debido al hecho de ser tierras periféricas, no conectadas a las redes de distribución superficiales, las "acciones de captación del control" (Borras, Franco et al., 2012) sobre estas extensiones suelen desarrollarse conjuntamente con la búsqueda de agua hidrogeológicamente disponible. Ahora bien, hay que especificar también que más allá de la ingeniosa estrategia de acceso al nexo agua-tierra, la puesta en producción de estas tierras depende de la implementación de modernos sistemas de riego, por goteo o por aspersión, según los cultivos. A continuación, nos centramos sobre esta verdadera conquista de los piedemontes en este 
oasis, haciendo especial hincapié en las estrategias de localización y conformación de zonas productivas relacionadas a la nueva vitivinicultura. Pero con el fin de resaltar que esta expansión no sólo concierne al sector vitivinícola y que la compleja relación producción-consumo (P-C) también opera en otros rubros, expondremos brevemente un caso de producción de papas destinadas a los fast-food.

\section{BUSCANDO EL TERROIR}

Un crítico de vinos del New York Times, en una visita a la provincia en 2016, parece haber retenido una tendencia clave del discurso de los "nuevos" vitivinicultores, ya que para "ir más allá del Malbec, hay que mirar debajo de la superficie" (Asimov, 2016). De hecho, un enólogo de un nuevo proyecto en el Valle de Uco comenta lo siguiente:

Antes no se miraba tanto el suelo sino más bien la altura y la temperatura hoy te diría que se mira más el suelo que el cielo, [...] porque es un suelo perfecto para vinos de alta gama, de alta calidad, son suelos aluvionales, suelos muy pedregosos y arenosos, es decir que son suelos que tienen mucho drenaje [...] esto hace que los vinos al final tengan una textura y un carácter muy distinto a otros (Entrevistado $\mathrm{N}^{\circ}$ ).

Ahora bien, este mismo profesional recordaba al mirar el viñedo que supervisaba que antes "no había nada, [...] no había plantas, todo era monte, era virgen". Efectivamente, para instalarse ahí y llevar a cabo un proyecto de agroexportación, su empresa tuvo que adoptar el paradigma técnico-científico-informacional y, más particularmente, el uso del riego por goteo. Tal y como resaltaba otro enólogo de la zona, la adopción del riego por goteo al principio de la década del 1990 fue "el verdadero detonante de la expansión" de nuevas zonas de cultivos vitícolas (Entrevistado $\mathrm{N}^{\circ} 3$ ). Esta tecnología no sólo facilita la producción sobre terrenos inclinados del piedemonte -ubicados en altura para lograr la mayor amplitud térmica- sino también sobre suelos rocosos y pedregosos, con escasa fertilidad e importante permeabilidad. La adopción de esta tecnología tiene, además, otras múltiples ventajas tal y como especifica un estudio del Instituto Nacional de Tecnología Agropecuaria (INTA):

va más allá del ahorro de agua ya que también aumenta el rendimiento de los cultivos y los hace más homogéneos, al recibir todos la misma cantidad de líquido. Otro beneficio [...] tiene que ver con el ahorro y optimización de los fertilizantes y agroquímicos y, por último, la reducción de la mano de obra, ya que para regar 50 hectáreas se necesita una sola persona (Porolli, 2017).

Ahora bien, en estas condiciones semiáridas, la gestión del riego por goteo es una etapa clave de los diferentes procedimientos de la agricultura de precisión. Una vez realizadas la referenciación geográfica, la parcelación geométrica y la 
sectorización del viñedo, el manejo del riego por goteo facilita la homogeneización del proceso productivo hasta la etapa de la vendimia separada. Un ingeniero que trabaja para una empresa extranjera cuyo "producto final esta apuntado a un mercado [donde] una botella en un retailer en EE.UU. está arriba de 30 dollars [sic]", explicaba que las distintas parcelas una vez "georreferenciadas" tienen que ser trabajadas "de forma diferente, con diferentes niveles nutricionales, diferentes niveles de riego" (Entrevista $\mathrm{N}^{\circ} 4$ ). Varias empresas utilizan entonces logiciales cartográficos para "sectorizar el viñedo" con el fin de identificar zonas diferentes y poder "actuar sobre las diferencias para tratar de volver a la homogeneidad" (Malizia, 2010). En este sentido, según una empresa de capitales franceses, la "idea es obtener zonas de cosecha homogéneas en cada parcela para poder ingresar uvas de mismas características en las piletas. El hecho de tener una cosecha homogénea incrementa el potencial de calidad del futuro vino" (Altavista, 2016). En general, para estas empresas, el uso de sistemas de información geográficos (GIS) se vuelve una herramienta cada vez más indispensable. En palabras del ingeniero:

puedes cosechar inclusive con GPS instalado en la máquina y cosechas sectores si, otros no. Una vez que vos polígonas, identificas con las coordenadas en el GPS, y luego entras en el cuadro y cosechas la parte del cuadro que te interesa. Yo creo que el futuro es eso. Todo este paquete tecnológico se llama vitivinicultura de precisión. (Entrevistado $\mathrm{N}^{\circ} 4$ ).

Ahora bien, si el bombeo de agua subterránea facilita claramente el despliegue de esta trama tecnológico-productiva, es menester mencionar que la viticultura de precisión también se puede llevar a cabo en proyectos alimentados por la red de distribución superficial de agua, pero siempre y cuando cuenten con piletas cubiertas de nylon, donde se acumulan los turnos y desde las cuales se distribuye el agua en la finca de forma presurizada. Sin embargo, tal y como lo recuerda un ingeniero de un importante holding chileno, "es más fácil regar con bombeo [pozos], es automático, uno [...] gira una perrilla y automáticamente se te riega, y puedes regar por bloques." (Entrevistado $\mathrm{N}^{\circ} 5$ ).

Estas últimas décadas asistimos, como bien destaca David Harvey, a "una creciente competencia internacional y globalización del consumo estandarizado del vino" (Harvey, 2007: 424). En este contexto y mediante la adopción del paradigma técnico-científico-informacional, los actores del modelo de agronegocios pueden, como declara orgullosamente el famoso enólogo Michel Rolland, "realizar buenos vinos en cualquier parte del mundo" (Yanke, 2018). Si bien nuestras observaciones se acotaron a Mendoza y al Valle de Uco, consideramos que pueden ser útiles para repensar ciertas transformaciones territoriales de otras regiones vitivinícolas agroexportadoras. 
IMAGEN 2. CAMPO DESBROZADO Y EVOLUCIÓN TEMPORAL DE UN PROYECTO VITÍCOLA EN SAN CARLOS 2003-2016
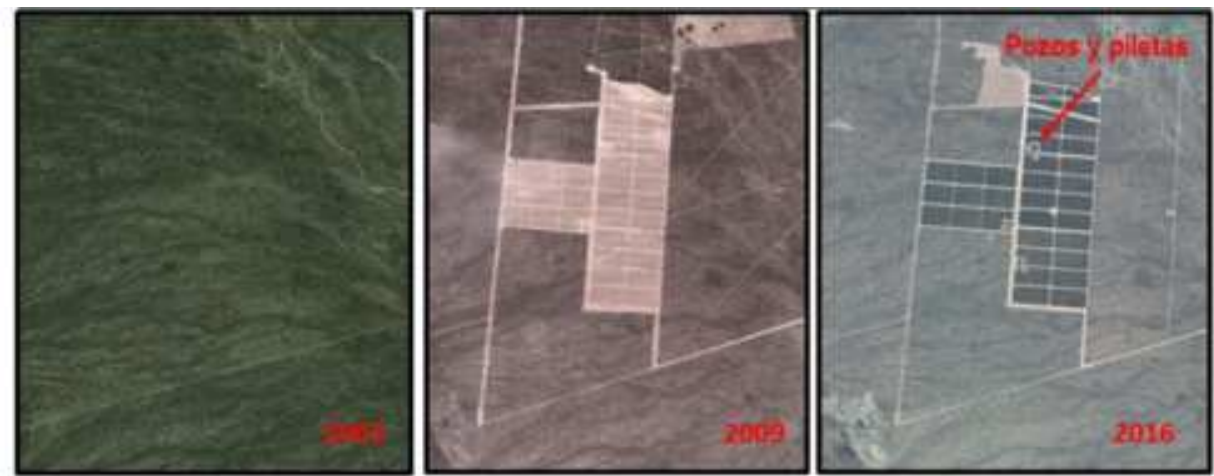

Fuente: elaboración propia en base a Google Earth.

\section{AGUA Y TIERRA AL SERVICIO DE LOS FAST-FOOD}

We use our world class potato knowledge to feed the world (Farm Frites, 2015).

Como en otras zonas áridas del planeta, la tecnología automatizada de los pivotes de riego ha incursionado estas últimas décadas en el paisaje semiárido mendocino, principalmente sobre tierras arenosas, más fértiles y poco accidentadas. En el sur del Valle de Uco, esta tecnología se ha implementado entre algunos productores hortícolas capitalizados y, particularmente, en torno a un importante emprendimiento de producción de papas industriales. Si bien este proyecto gira en torno a un intermediario empresarial argentino -primo del expresidente Mauricio Macri-, fue inicialmente capitaneado por el holding transnacional Farm Frites, y se encuentra actualmente en mano de otro "imperio del agrobusiness", Simplot. Sin pretender especificar estas maniobras empresariales (Larsimont, Carballo, Ivars, 2018), lo que nos interesa aquí es describir las estrategias de localización y de producción de este tipo de emprendimiento. En este sentido cabe entender el origen de este proyecto en el marco de la estrategia transnacional del holding holandés, un "jugador realmente global y líder en la producción y comercialización de papas" (Farm Frites, 2016). Detrás de este lema neo-maltusiano de buscar "alimentar el planeta", encontramos ocho plantas de producción, ubicadas sobre cuatro continentes y que se especializan geográficamente en el abastecimiento de grandes cadenas de fast-food, pero también de hoteles y supermercados. En esta trama, su ubicación en Argentina se tiene que entender como una 
estrategia de abastecimiento del mercado del cono sur, principalmente Brasil. Más precisamente, la localización del emprendimiento en Mendoza fue elegida después de un minucioso proceso de selección donde, como en otras zonas de producción, las condiciones agro-climáticas de la provincia y la disponibilidad de agua subterránea fueren criterios claves ${ }^{17}$.

Ahí en San Carlos, en los márgenes sur del Valle de Uco, encontraron "características únicas para el desarrollo, crecimiento y posterior almacenamiento de papas" (Manoni, 2011). Podemos destacar en base a nuestras entrevistas una serie de criterios de selección de estas tierras que según un encargado "no servían ni para animales" (Entrevistado $\mathrm{N}^{\circ}$ 6). Buscaban, precisamente, "suelos vírgenes", arenosos y, si es posible, alejados para conservar las buenas condiciones sanitarias y edafológicas del suelo. Este requisito iba de la mano con la necesidad de adquirir grandes extensiones de tierra, poco accidentadas para facilitar la rotación de cultivos y la instalación de sistemas de riego tecnificados de pivote central ${ }^{18}$. La implementación de esta tecnología de riego estaba sujeta a otro criterio imprescindible: la disponibilidad de agua subterránea (Imagen 3). Finalmente, cabe destacar un criterio de orden climático que implica una amplitud térmica y unas temperaturas promedio óptimas para el desarrollo del cultivo -entre octubre y abril-, así como la escasez de precipitaciones. Esta escasez no debe entenderse como una condición a remediar sino más bien como una ventaja en el proyecto productivo que se plantea, por supuesto siempre que se disponga de aguas subterráneas y del sistema adecuado de aspersión. En estas grandes extensiones de terreno y con estos equipos de riego por pivote los técnicos garantizan "la cantidad de agua necesaria para el cultivo" (La Nación, 2011), su crecimiento controlado y homogéneo $\mathrm{y}$, finalmente, la entrega de las papas en tiempo y forma a la principal planta de procesamiento que tienen en la localidad de Munro ${ }^{19}$, sita al sur de la provincia de Buenos Aires, y desde la cual se distribuyen a diferentes mercados del cono sur. Bajo estas condiciones ideales, los profesionales entrevistados se jactan de producir una papa "perfecta, sin impureza y con una forma

\footnotetext{
${ }^{17}$ Cabe al respecto resaltar que varias de sus otras plantas de producción se encuentran también en zonas áridas tales como Egipto, Kazajstán, China, etc. y son irrigadas por pivotes de riego.

${ }^{18} \mathrm{El}$ proyecto cuenta con nueve pozos de, aproximadamente 150 metros de profundidad, cada uno de los cuales es suficiente para regar 50 hectáreas simultáneamente (Entrevistado ${ }^{\circ} 6$ ).

${ }^{19}$ Cabe mencionar que el holding Farm Frites se proveía también de papas del sudeste bonaerense cultivadas sin riego artificial debido a las mayores precipitaciones de esta región. Sin embargo, al contario de sus prácticas productivas en Mendoza, en la provincia de Buenos Aires, el cultivo era más vulnerable a la variabilidad climática y no se garantizaba el continuo abastecimiento de la planta procesadora.
} 
impecable" (Entrevistado $\mathrm{N}^{\circ} 7$ ); una papa "crocante [y] que cumple con las expectativas del consumidor" (Entrevistado. $\mathrm{N}^{\circ}$ ). En definitiva, al adoptar el paradigma técnico-científico-informacional producen una papa ideal para su procesamiento industrial y comercialización en los fast-food, ya que como decía otro de ellos al señalar las grandes extensiones verdes en medio del desierto "sin Mc Donald no piensas en esto" (Entrevistado $\mathrm{N}^{\circ} 6$ ).

A modo de cierre de este apartado, cabe recordar que al final de la década de los 80 y a inicios de los 90, llegaron masivamente a Sudamérica los llamados fast-food, entre otros establecimientos de alimentos procesados. Lo que quisimos mostrar con este ejemplo de grabbing es que la macdonaldización de la sociedad (Robbins, Hintz, Moore, 2010), más allá de introducir nuevas formas de consumo, incide claramente en la organización de la producción, en este caso de la papa. Sin embargo, podemos pensar en otros muchos productos. Estos grandes holding corporativos encontraron en Mendoza, y en la proliferación de los fastfood del Cono Sur, un ámbito ideal para desplegar sus estrategias empresariales, conectando nuevos espacios productivos a nuevos espacios de consumo.

\section{MARCAS DE DISTINCIÓN, SEDUCCIÓN VISUAL Y ESTILO DE VIDA.}

A continuación argumentamos que la singular relación producción-producción que observamos en la agricultura de precisión opera también de forma particular en otro fenómeno relacionado a la conquista de los piedemontes. Nos referimos a la continua búsqueda de marcas de distinción asociada al mundo del vino y a la proliferación de proyectos empresariales que combinaron la exportación vitivinícola con actividades turísticas e inmobiliarias. Para entender esta tendencia partimos de lo que resalta David Harvey con respecto al mundo cada vez más competitivo del vino. Según él, el comercio del vino, más allá de una "cuestión de dinero y beneficio", es, profundamente, una cuestión cultural; "desde la cultura del producto a las prácticas culturales que rodean su consumo y el capital cultural que puede desarrollarse entre productores y consumidores" (Harvey, 2007: 425).

Por lo tanto, en la experiencia, lo que encontramos es toda una serie de "discursos opuestos, todos con diferentes reivindicaciones de verdad" sobre criterios de singularidad, originalidad y autenticidad, no sólo de los productos sino de las regiones productivas (Harvey, 2007: 425). De esa manera, ahora más que nunca, las regiones productoras tienen que trabajar colectivamente sus respectivas imágenes, "realzando sus virtudes por medio de sus símbolos heredados o reciente- 
mente elaborados [...]" (Santos: 2000: 227). En este sentido, podemos decir que la provincia de Mendoza, al desarrollar robustamente el eno-turismo (Torres et al., 2018) y al "utilizar la imagen del lugar como imán" (Santos, 2000: 227) se ha insertado en una "guerra de lugares" (Santos, 2000: 209).

IMAGEN 3. LOCALIZACIÓN DEL PROYECTO FARM FRITES SAN FILI Y GESTIÓN A DISTANCIA DEL RIEGO POR PIVOTE. FEBRERO DE 2015.

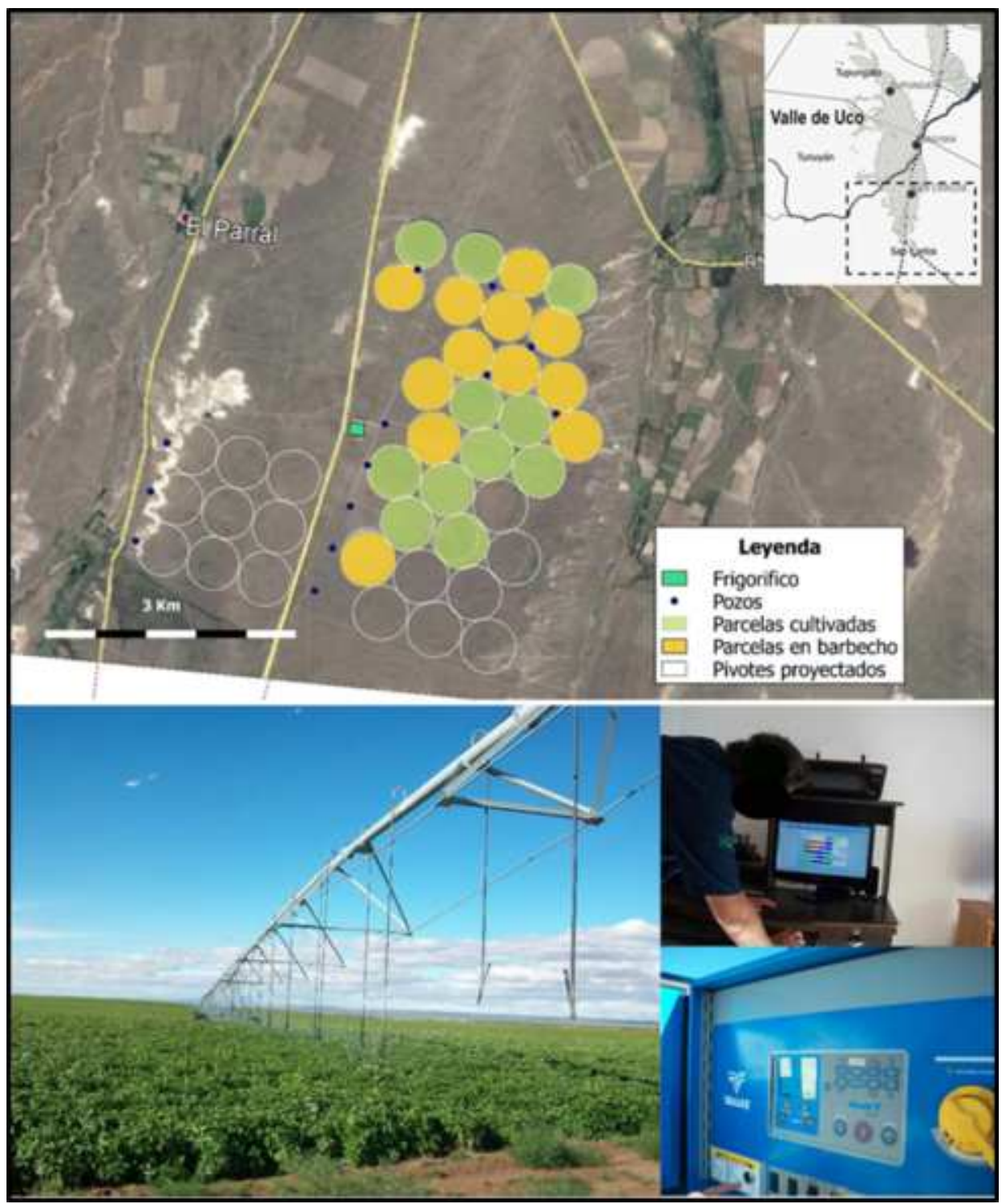

Fuente: elaboración propia. 
Ahora bien, si la provincia de Mendoza se ha constituido estas últimas décadas como una de las famosas capitales internacionales del vino, no fue solo por sus exportaciones sino también, e indudablemente, por haber seguido la tendencia mundial de combinar la actividad agro-productiva con la puesta en escena del ámbito de producción. En este sentido, las empresas vitivinícolas que lideraron la conquista de los piedemontes han contribuido sustancialmente a este proceso. Efectivamente, para estas empresas, la búsqueda de marcas de distinción, lejos de acotarse al producto final, la botella de vino, apunta en general también al ámbito de producción, la bodega y su viñedo. Tal y como mencionaba un prestigioso arquitecto local, "el mercado dicta reglas que combinan arte arquitectónico y paisajístico [...] y la "idea clave es saber jugar con volumen y espacio" (Flores, 2001: 57). Dicho de otra manera, el diseño arquitectónico y paisajístico o la belleza escénica -con vista sobre la cordillera nevada- se conformaron para muchas empresas como un valor agregado, como una "seducción visual con fines comerciales" (Flores, 2001: 54).

Bajo esta lógica, si la simbología tiene especial importancia en la arquitectura de las bodegas (Imagen 3), el diseño paisajístico cobra cada vez más relevancia en muchos proyectos, y, a veces, de manera muy extravagante. Gracias a las nuevas tecnologías de la agricultura de precisión, algunos proyectos buscaron romper con las formas cuadriculares y funcionales de las parcelas, e introducir al contrario curvas y círculos (Imagen 4). A la luz de estas exuberantes puestas en escena de la naturaleza, las palabras siguientes de Henri Lefebvre cobran especial relevancia:

Tengamos muy presente que esos espacios poseen un carácter visual cada vez más pronunciado. Se los fabrica para ser concebidos en el plano de lo visible: visibilidad de gentes y cosas, de espacios y de todo aquello que estos contengan. En tanto que rasgo dominante, la visualización (más notable que la espectacularización que por otro lado incluye) sirve para enmascarar la repetición (Lefebvre, 2014: 132).

Por otra parte, y en paralelo a la expansión de la nueva vitivinicultura, cabe mencionar la proliferación de proyectos que combinan actividades productivas con desarrollos inmobiliarios y de ocio. Cabe en particular destacar la propagación del llamado winecountry; es decir "un proyecto que en realidad es más inmobiliario que vitivinícola. Es como un barrio privado, pero de viñas" (Entrevistado $\mathrm{N}^{\circ}$ 2). Para estos casos la mirada lefebvriana también ayuda a subrayar la lógica subyacente, al considerar que: "lo «inmobiliario», [como] producción y especulación difícilmente discernible de la «promoción», oscila entre un papel subordinado de reactivación, reserva o apoyo, y un papel dominante" (Lefebvre, 2014: 370). 


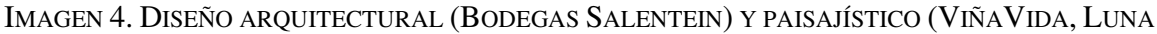
Austral, ERNesto Catena Vineyards).

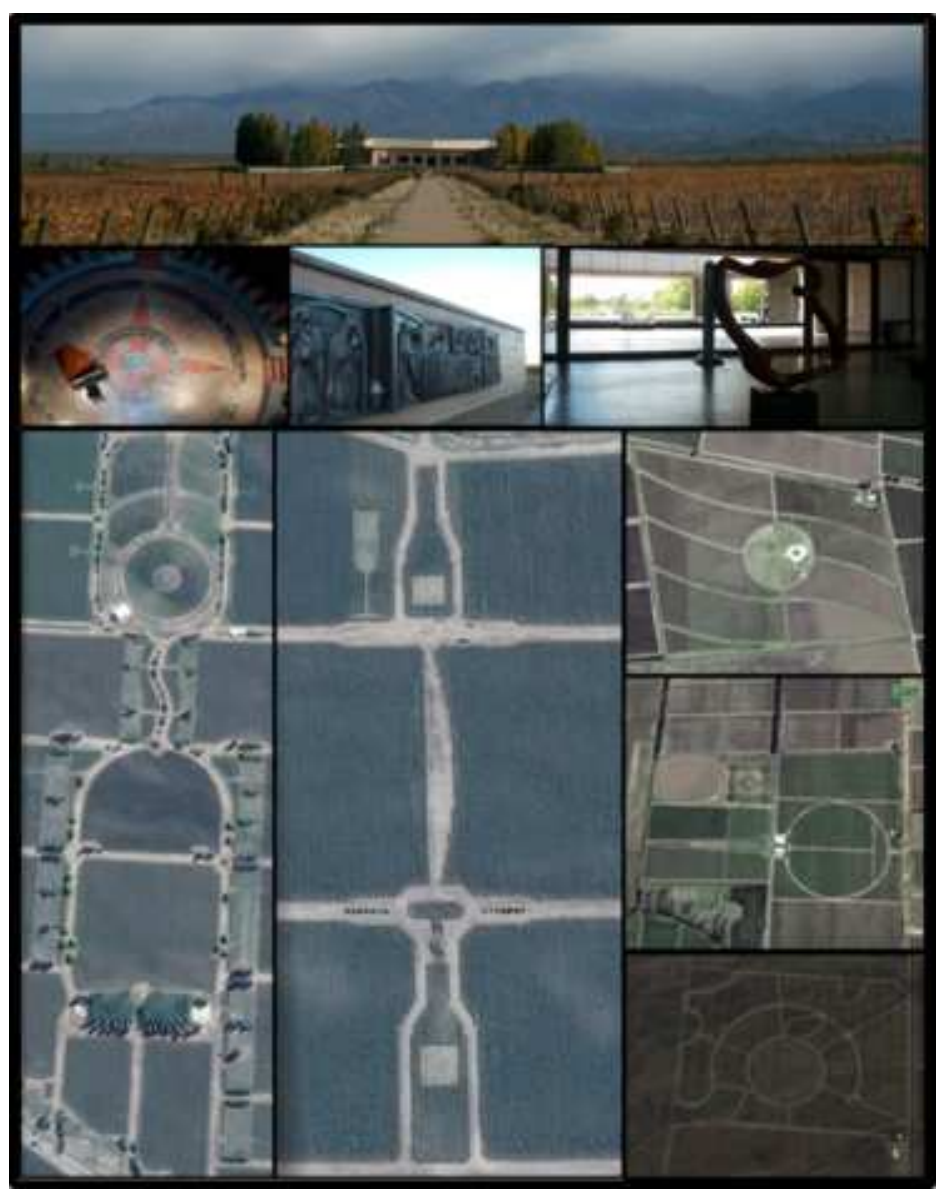

Fuente: elaboración propia. Fotos del autor y Google Earth (2015)

Es más, podemos ver en este tipo de inversión inmobiliaria y en los tiempos largos del vino un ejemplo de lo que algunos autores calificaron de acaparamientos de rentas (Andreucci, García-Lamarca, Wedekind, Swyngedouw, 2017). Ahora bien, lo que nos interesa resaltar con este tipo de proyectos es que parecen coincidir en la meta de ofrecer a sus clientes un "estilo de vida". Un caso emblemático en el Valle de Uco, pero que habla para otros, es el proyecto Tupungato Winelands, perteneciente a un holding inmobiliario de capitales belgas (Larsimont, 2016). En uno de sus primeros folletos promocionales, la empresa presentaba el campo adquirido en 2008 como un desierto "repleto de ríos subterráneos de agua dulce" que iba a transformarse en "un oasis donde la naturaleza se des- 
pliega resguardando el potencial de un verdadero tesoro". En efecto, la perforación de varios pozos permitió "hacer cosas diferentes de las típicas", como combinar, sobre 800 hectáreas de campos semidesérticos, viñedos, residencias privadas, hoteles de lujo, y canchas de polo y de golf. En este mismo folleto invitan a sus clientes a "vivir el proceso de alquimia e interacción con la naturaleza" y recuerdan que "ser parte de Tupungato Winelands es vivir una nueva forma de lujo: la belleza de lo eterno" (Tupungato Winelands, 2009).

Sintetizando, podemos decir que este tipo de proyectos proponen a sus clientes una naturaleza experimentada, producida acorde a ciertos estándares internacionales de lujo. $\mathrm{Al}$ apuntar a determinado tipo de clientes, estas ofertas turísticas e inmobiliarias, si bien se presentan como "experiencias auténticas", responden en realidad a expectativas comunes a una determinada comunidad de elite global. En este sentido, de la misma manera que con las grandes cadenas de hoteles de lujo, tales como Sheraton, lo importante es garantizar a sus clientes un explícito ranking de comodidades que les permita disfrutar de su visita o experiencia en Mendoza con las mismas comodidades que en otra capital internacional del vino. Ahora bien, este tipo de puesta en escena de la naturaleza no sólo implica un consumo intensivo y excesivo de agua, sino que además contrastan fuertemente con las realidades locales de los pobladores que viven en sus alrededores. La llegada del "nuevo vecino" Tupungato Wineland ha sido particularmente violenta, tanto material como simbólicamente (Larsimont, 2016). Al recordar esta espectacular inauguración un vecino entrevistado afirmaba: "con la presencia de celebridades, globos y avionetas [...] nos dimos rápidamente cuenta que íbamos a quedarnos fuera de este proyecto" (Entrevistado $\mathrm{N}^{\circ} 9$ )

Por su parte, otra vecina, directamente afectada por un violento proceso de desalojo, comentaba al contemplar desde una colina y detrás de un alambre que una "cosa es transformar la naturaleza, otra es reventarla" (Entrevistado $\mathrm{N}^{\circ} 10$ ).

\section{IDEOLOGÍA DE LA EXPANSIÓN Y DE ENCUBRIMIENTO}

En Mendoza todavía suman millares las hectáreas por conquistar: la agricultura puede expandirse y mejorarse, tecnificarse la riqueza pecuaria, localizarse nuevos mercados, a los cuales es posible dominar con cantidad y, especialmente, calidad de productos (Marzo, Inchauspe, 1967: 374).

Desde finales del siglo XIX hasta bien entrado el siglo XX, la producción de los oasis mendocinos ha sido dominado por "nubes ideológicas" de progreso, de misión histórica y de civilización (Lefebvre, 1973), dejando incluso, como ya mencionamos, ciertas secuelas de la célebre díada "civilización o barbarie". 
Como otras muchas conceptualizaciones binarias hasta ahora no superadas, la idea de un desierto "desaprovechado" ha alimentado una ideología de la expansión de la frontera de los oasis. A la luz de los ejemplos que hemos expuesto hasta ahora, el deseo que expresaban los geógrafos mendocinos Marzo y Inchauspe al final de la década de los años 1960 (ver epígrafe) parece estar cumpliéndose hoy en día, por lo menos por algunos actores. Ciertos grupos empresariales no dudan en resaltar su contribución a esta conquista, tomándolo como asunto casi personal, tal y como es el caso de Bodega Salentein. En el año 2015 este holding holandés lanzaba una nueva campaña publicitaria en los medios de comunicación, en su página web y en la vía pública, bajo el eslogan "Fundamos una bodega. Transformamos una región". Exponían una fotografía antigua del Valle de Uco, como un "monte desértico", a la cual se le superponía otra, actual, con un sendero bordeado de viñedos que desemboca en su moderna bodega. El contraste entre la toma antigua, en blanco y negro, y la actual, en color, estaba resaltado también por las referencias al "Ayer" y al "Hoy". Tal y como sostenían los responsables de marketing de la empresa:

Esta campaña refleja el compromiso que Bodegas Salentein ha tenido con el Valle de Uco en estos primeros 20 años de transformación, contribuyendo en convertir un desierto en una región vitivinícola ícono a nivel mundial, y a cada uno de nuestros vinos en una fiel expresión del mismo. (TotalMedios, 2015).

Ahora bien, la vigencia de ciertas formaciones discursivas regionales relativas a la potencialidad de una extensión de los oasis sobre el desierto no sólo permea las narrativas del mundo empresarial sino también del mundo ingenieril, académico y, por supuesto, político. Según declaraba un político que estuvo a cargo del Departamento General de Irrigación: "Si nosotros regáramos bien, si utilizáramos bien el agua, Mendoza podría ser California. Podríamos pasar de las 300 mil hectáreas cultivadas al millón de hectáreas con el agua que hoy tenemos disponible" (ARN Diario, 2010).

Tal y como específica la anterior declaración, la expansión de los oasis como proyecto político va de la mano con una búsqueda de eficiencia del sistema de riego. En este sentido, y dando igualmente cuenta de un deseo expansionista, un técnico de apoyo a las inversiones de la FAO en Mendoza resaltaba en un informe la necesidad de "analizar el potencial de creación de nuevas áreas" (Loyola, 2015). Aunque evaluaba más cuidadosamente el potencial de expansión al $11 \%$ de la superficie actual, destacaba la necesidad de "identificar y evaluar la incorporación de agricultura irrigada, en zonas que actualmente no se encuentran en producción, y cuentan con condiciones agroecológicas adecuadas y disponibilidad de recursos hídricos" (Loyola, 2015). 
Consideramos que, con semejantes declaraciones, las organizaciones empresariales que lideraron la reciente expansión de la frontera agrícola -y que pretenden poner en valor "tierras vírgenes" y "desaprovechadas" aplicando tecnologías modernas de riego- gozan de cierta legitimidad al ser consideradas y publicitadas como "eficientes en tanto modernas" (Entrevistado $\mathrm{N}^{\circ} 11$ ). Dicho de otra manera, encarnarían precisamente y para muchos el "modelo exitoso", ambientalmente sostenible y que hay que seguir. Al contrario, los casos de conquista del piedemonte del Valle de Uco que describimos anteriormente mostraron que el uso de modernas tecnologías de riego por goteo o por aspersión responde, más allá de una cuestión de eficiencia económica, a patrones organizacionales que garantizan una reproductibilidad de los productos acorde a criterios de calidad y cantidad. Consecuentemente, consideramos que hay que estar atento y saber dar cuenta tanto de ciertas concepciones dominantes sobre la naturaleza, como del sutil manejo por parte de estos actores empresariales del actual discurso ambiental, en el cual todo tiende a calificarse de "verde" y "sostenible", también conocido como el greenwashing. Efectivamente, se logra constituir una sutil amalgama en torno al manejo respetuoso de la naturaleza, la exaltación de las bondades de la tecnología y el éxito empresarial, y es menester destacar que en muchas ocasiones la "sostenibilidad" se asocia directamente con la "eficiencia" y la "ganancia económica". La siguiente afirmación de una empresaria del Valle de Uco va particularmente en este sentido:

Nuestra finca cuenta con todas las hectáreas con riego presurizado, todo lo que es viña está con goteo, lo que son frutales con microaspersión [...] estoy en un trabajo donde ser sustentable tiene que ver con ganar dinero, no con la codicia, sino con ganar dinero para seguir generando inversión (Entrevistado $\mathrm{N}^{\circ} 12$ ).

A esta altura cabe precisar que los acaparamientos de tierras, y más generalmente la expansión del modelo de agronegocios, no son procesos lineales en los cuales las organizaciones empresariales logran siempre cumplir con sus objetivos de negocio. Por el contrario, se evidencian caminos más bien sinuosos, donde una serie de trabas y obstáculos implican a veces hacer marcha atrás. Si estos obstáculos tienen que ver con altibajos de orden político-económico - pensamos particularmente a la encrucijada de los últimos cambios de gobierno nacional-, resaltamos en este artículo un obstáculo de orden más bien jurídico-administrativo, relativo a la implementación de una serie de medidas de restricción para realizar nuevos pozos. Efectivamente, a lo largo del trabajo hemos destacado que un determinante clave para poner en producción estas tierras periféricas era la posibilidad de perforar pozos. Ahora bien, si hubo una época en la cual sacar "un pozo era como sacar un número en la carnicería" como ironizaba un secretario de ges- 
tión hídrica del DGI (Entrevistado $\mathrm{N}^{\circ} 13$ ), el panorama actual de acceso al agua subterránea ha cambiado drásticamente. Esta última década, la posibilidad de conseguir un permiso de perforación se ha visto obstaculizada por la implementación de un cepo en consecuencia de la declaración de sobreexplotación de los principales acuíferos de la zona, como es el caso de la Resolución 722/2011 que concierne al Valle de Uco. Para muchas organizaciones empresariales, este cepo se presentó como un verdadero limitante, tal y como lo relata una empresa vitivinícola en su página web: "el problema consistía en que, a pesar de los magníficos suelos y oportunidades de hacer crecer un viñedo donde florece un malbec con magníficos taninos a caliza y frutos frescos, los derechos de agua no fueron concedidos en la región". (Altos Las Hormigas, 2015)

Por su parte, una profesional de la empresa holandesa Farm Frites nos explicó que esta restricción "imped[ía] a la empresa agrandarse" y que "está todo el mundo esperando que se abran las autorizaciones" (Entrevistado $N^{\circ} 8$ ). A continuación, exponemos de qué manera esta traba jurídico-administrativa se presentó como un síntoma de la presión del modelo de agronegocio no sólo solo sobre el agua subterránea sino también sobre los pequeños y medianos productores, "restos del náufrago" de las sucesivas crisis (Ratier, 2013). Presentamos dos principales formas de presión.

En primer lugar, tal y como lo consideramos en otro trabajo (Martin, Larsimont, 2016), cabe mencionar que se implementó rápidamente cierta flexibilidad al complejo y contradictorio cuerpo de resoluciones implementadas para prohibir o autorizar nuevas perforaciones en la zona. Por ejemplo, para el Valle de Uco se aplicó la Resolución 164/2013, que establecía la posibilidad de "acceder a un nuevo permiso de perforación en reemplazo de otro existente en la misma cuenca y/o acuífero". Como recuerda una nota periodística: “[...] corrió como reguero de pólvora entre los empresarios agrícolas del Valle de Uco, generando, en algunos casos, una frenética búsqueda de títulos" (Manoni, 2013).

Es, precisamente, la situación que pudimos revelar entrevistando a un pequeño productor frutícola de zona: “a mí me han querido comprar el pozo que tengo. [...] Ni sé cuánto vale, pero como a mí me hace falta esto, no lo puedo vender, tengo cuatro hijos y mi señora" (Entrevistado $\mathrm{N}^{\circ} 14$ ). Ahora bien, esta posibilidad de remplazo y comercialización suscitó una ola de críticas en la prensa, aunque su alcance fue limitado.

Por lo tanto, y, en segundo lugar, la presión del modelo de agronegocios se evidenció también con la búsqueda de tierras cultivadas por pequeños y medianos productores con pozos habilitados. Como especificaba una ingeniera agrónoma 
"hoy por hoy, cualquier campo se cotiza por los pozos que tiene" (Entrevistado $\mathrm{N}^{\circ} 15$ ). De esa manera, en ciertas zonas altas del Valle de Uco, actores fuertemente capitalizados consiguieron comprar las tierras de pequeños y medianos productores hortofrutícolas, que sufrían una prolongada crisis del sector. Estas son las palabras de un mediano productor que no pudo adherir su empresa al paradigma técnico-científico-informacional y que tuvo que vender su tierra:

la fruta ya dejó de ser negocio y [en] esa zona más que nada [...] tiene que ser empresas que tengan muy buen poder, o sea muy bien ubicada la mercadería. Por una cuestión de que el agro paso a ser a que no podés ser chico, [debes] ser grande o dedicarte a otra cosa. (Entrevistado $\mathrm{N}^{\circ} 16$ ).

Como también recordaba otro primo suyo, al contrario, y a pesar de tener sus frutales abandonados, sigue resistiendo a cualquier oferta, hasta el momento: "hay gente que le quiere comprar, él no tiene el dinero para hacer la inversión y no quiere salirse de la rueda tampoco porque usted vende y no vuelve a comprar más ahí arriba" (Entrevistado $\mathrm{N}^{\circ} 16$ )

Por su parte, un ingeniero que trabaja para varias empresas en la zona anticipaba que se "va a producir, sin ninguna duda, una diferenciación de las características de cultivos en función de la renta del producto, esto es lo que va a pasar". (Entrevistado $\mathrm{N}^{\circ} 4$ ). A modo de síntesis, podemos decir que este avance del modelo de agronegocios en ciertas zonas altas del Valle de $\mathrm{Uco}^{20}$, al presionar los "restos del náufrago", da cuenta de un progresivo proceso de selección territorial eco-eficiente (Larsimont, 2018). En este proceso, las estrategias y prácticas de actores hegemónicos contribuyen no sólo al ocultamiento o la elusión de otras prácticas agro-culturales tradicionales sino también a su creciente eliminación de las nuevas áreas estratégicas de producción del oasis.

\section{PALABRAS FINALES}

En este artículo, propusimos una comprensión profunda del complejo proceso de acaparamiento de tierras en los oasis de la provincia de Mendoza, en particular en el Valle de Uco. Tratamos de desentrañar los procesos que rigen el

\footnotetext{
${ }^{20}$ Es interesante resaltar que en el actual contexto de limitación de nuevas perforaciones, ha surgido estos últimos años un nuevo interés por parte de organizaciones empresariales del MA para proyectos públicoprivados de abastecimiento de agua superficial. Podemos, por ejemplo, mencionar el caso emblemático del proyecto de venta por parte del Estado del enorme terreno militar de Campo de Los Andes, ubicado en la zona Premium del Valle de Uco (ver Saldi, Scherbosky, 2018). Ahora bien, los actores capitalizados a los cuales aludimos en este trabajo parecen contemplar la potencialidad de estos nuevos proyectos basados en fuentes superficiales, siempre y cuando se garantice una distribución presurizada y medida de agua. Efectivamente, el uso de sistemas de riego modernos sigue siendo una dimensión clave para llevar a cabo la agricultura de precisión que está al servicio de sus objetivos de negocio.
} 
control sobre determinados espacios rurales, tomando en cuenta no sólo el suelo y el sobresuelo, sino también el subsuelo (Lefebvre, 2014). En este sentido, en los casos que hemos presentado, además de las características edáficas, agroclimáticas y paisajísticas, hemos insistido en que la presencia de agua subterránea cobraba especial relevancia en las estrategias de localización empresarial. Al respecto, podemos afirmar que estas últimas décadas se conformaron verdaderos "acuatenientes corporativos" en los márgenes de los oasis. Desde estas posiciones periféricas, estos actores gozan de una ventaja operativa en cuanto al acceso al recurso ya que "reciben agua cuando la requieren, en tiempo y forma (no 'cuando viene')" (Navarría, 1999). Es más, podemos decir que lograron desacoplarse del tradicional sistema de gestión de la distribución superficial del recurso, consolidando de esa manera un sistema de acceso individual y privatista al agua.

Ahora bien, hemos insistido también en la necesidad de entender estos procesos de acaparamientos múltiples, no sólo en un registro técnico-material sino también discursivo y simbólico. Más concretamente, hemos considerado central prestar especial atención a las formaciones discursivas regionales o eco-tecnocráticas a las cuales se acoplan ciertas estrategias de marketing empresarial.

En relación a las actividades agro-productivas, utilizamos nuestras herramientas teóricas para de-construir ciertas narrativas empresariales como esta supuesta hazaña de "empezar de cero" sobre tierras "vírgenes" y "desaprovechadas", pero particularmente esta fuerte idea de ser "eficiente en tanto moderno". Hemos argumentado al contario, que para estos actores empresariales, estas ubicaciones periféricas y el uso de tecnologías modernas se presentaban más bien como ventajas operativas de acuerdo a sus planes de negocios. En particular, hemos tratado de demostrar que la implementación de las modernas tecnologías de riego -por goteo o aspersión - apuntaba tanto a facilitar la reproductibilidad de las mercancías -en calidad y cantidad-, como a garantizar el abastecimiento y su posicionamiento en determinados mercados globales. Mencionado eso, quisimos mostrar que lo "único y singular" de un producto considerado "especial" tiene en realidad que ser repetible, y para lograrlo hay que tender a la homogeneización del proceso productivo. Esta homogeneización es requerida cada vez más para poder cumplir y satisfacer las demandas y los propios gustos creados de los consumidores. De ahí toda la pertinencia de decir que el "modo de producción crea el modo de consumo"; sea en referencia a las "papas globales" -disponibles en todos los rincones del planeta- o más específicamente en el caso del vino Premium, donde también opera a "una globalización del consumo estandarizado del vino" (Harvey, 2007: 424). 
Hemos argumentado también que una contradicción parecida de esta lógica producción-consumo se presentaba en la proliferación de proyectos vitivinícolas relacionados con actividades turísticas y/o inmobiliarias complementarias. Mostramos que este tipo de acaparamientos de tierras se presentaba como un factor clave en la conformación de una ruralidad "idílica" y mercantilizada, pero a su vez que la continua búsqueda de marcas de distinción tendía, al fin y al cabo, a que la originalidad sea cada vez más efímera. Dicho de otra manera, pensamos que esta pesquisa de criterios de singularidad ante las expectativas de los visitantes o consumidores, a pesar de las tentativas para "enmascarar la repetición" (Lefebvre, 2014: 132), tiende de alguna manera hacia la homogeneización y banalización de la experiencia.

Como palabras finales, podemos decir que, en aras de su rentabilidad y racionalidad intrínseca, las organizaciones empresariales a las cuales aludimos en este artículo tienden a subordinar las realidades socio-ambientales locales a una lógica extractivista global. Sus temporalidades empresariales contrastan con la de los espacios en los que se asientan, evidenciando un fuerte desacople con los tiempos geológicos necesarios para la recarga de acuíferos, la reconstitución de los suelos y con las dinámicas de los productores tradicionales y de los pobladores. En este artículo, y desde una mirada vertical y atenta a las dimensiones materiales, discursivas y simbólicas, quisimos dar cuenta de la complejidad de estos procesos de acaparamientos de tierras que "destruye[n] el porvenir en provecho de intereses inmediatos mientras arruina[n] el presente en nombre de un futuro programado y sin embargo incierto" (Lefebvre, 2014: 370).

\section{BIBLIOGRAFIA}

Allan, J., Keulertz, M., Sojamo, S., Warner, J. (eds.). (2013). Handbook of Land and Water Grabs in Africa: Foreign Direct Investment and Food and Water Security. Londres, Reino Unido: Routledge. https://doi.org/10.4324/9780203110942

Alta Vista. (2016). Terroir|Altavista Wines. Recuperado de http://www.altavistawines.com/terroir/

Altos Las Hormigas. (2015). Inicio - Altos Las Hormigas. Recuperado de http://es.altoslashormigas.com/

Altschuler, B. (2012). Fronteras sociales y asimetrías en la vitivinicultura mendocina actual. Cuadernos de desarrollo rural, 9(68), pp.151-175.

Altschuler, B, Collado, P. (2013). Transformaciones en la vitivinicultura mendocina en las últimas décadas: el doble filo de la estrategia cooperativa. Voces en el Fenix, (1), pp. 78-83.

Andreucci, D., García-Lamarca, M., Wedekind, J., Swyngedouw, E. (2017). "Value Grabbing": A Political Ecology of Rent. Capitalism Nature Socialism, 28(3), pp. 28-47. https://doi.org/10.1080/10455752.2016.1278027 
ARN Diario. (2010, 3 de enero). Abihagle: "Si hiciéramos las cosas bien podríamos ser como California”. ARN Diario. Recuperado de http://www.arndiario.com/notas/ver/id/261/2016-11 02/Abihagle+Si+hicieramos+las+cosas+bien+podriamos+ser+como+California

Asimov, E. (2016, 11 de febrero). To Move Beyond Malbec, Look Below the Surface. The New York Times. Recuperado de https://www.nytimes.com/2016/02/17/dining/malbec-mendozawine.html

Atkins, P., Bowler, I. (2001). Food in Society: Economy, Culture, Geography. Londres, Reino Unido: Arnold.

Bernardes, J., Maldonado, G. (2017). Estratégias do capital na fronteira agrícola moderna brasileira e argentina. En J. Bernardes, S. Federico, C. Gras, V. Hernández, G. Maldonado, (eds.) Globalização do agronegócio e land grabbing: A atuação das megaempresas argentinas no Brasil (pp. 57-81). Rio de Janeiro, Brasil: Lamparina.

Borras, S. M., Franco, J. C., Gómez, S., Kay, C., Spoor, M. (2012). Land grabbing in Latin America and the Caribbean. The Journal of Peasant Studies, 39(3-4), pp. 845-872. https://doi.org/10.1080/03066150.2012.679931

Borras, S. M., Kay, C., Gómez, S., Wilkinson, J. (2012). Land grabbing and global capitalist accumulation: key features in Latin America. Canadian Journal of Development Studies, 33(4), pp. 402-416. https://doi.org/10.1080/02255189.2012.745394

Carballo, O. (2019). Concentración y resistencias en la producción hortícola del Oasis Norte y Centro de Mendoza: Argentina [tesis de doctorado]. Córdoba, Argentina: Universidad Nacional de Córdoba.

Chazarreta, A. (2013). Capital extranjero y agroindustria. Notas para una discusión sobre los cambios en la burguesía vitivinícola de Argentina a partir de la década del '90. Mundo Agrario, 13(26), pp. 1-25.

Chazarreta, A. (2019). Transformaciones recientes de las actividades vitivinícolas en Argentina y avance del agronegocio, 1990-2010. Revista Latinoamericana de Estudios Rurales, 4(7), pp. 1-29.

DACC. (s.f.). RUT: Registro de Uso de la Tierra 2008-2014. Mendoza: Dirección de Agricultura y Contingencias Climáticas. Recuperado de http://www.contingencias.mendoza.gov.ar/web1/

DEIE-INDEC. (s.f.) Censos Productivos: Censo Nacional Agropecuario 1988 y 2002. Recuperado de http://www.deie.mendoza.gov.ar/\#!/censos-productivos

Delgado Cabeza, M. (2010). El sistema agroalimentario globalizado: Imperios alimentarios y degradación social y ecológica. Revista de Economía Crítica, (10), pp. 32-61.

DGI. (s.f.). Sistema de Información Catastral y Registral (S.I.C.A.R.). Recuperado de http://www.irrigacion.gov.ar/mapserver/sicar_web_produccion/dinamicos/comunes/p_vvaria/index.html

Erice, M. V. (2013). Necesidad de transparencia y legalidad en la gestión y uso de las aguas subterráneas (el reciente caso de la provincia de Mendoza). Derecho y Ciencias Sociales, (9), pp. 191-202.

Fairhead, J., Leach, M. Scoones, I. (2012). Green grabbing: a new appropriation of nature? Journal of Peasant Studies, 39(2), pp 237-261. https://doi.org/10.1080/03066150.2012.671770 
Farm Frites. (2015). Sustenability Report. Recuperado de https://www.farmfrites.com/media/document/001469_farmfrites-sustainabilityreport-english-version.pdf

Farm Frites. (2016). Farming, it's in our nature. Recuperado de https://www.farmfrites.com/ourstory/10/farm.html

Flores, M. (2001). El diseño integrado al paisaje como valor agregado. Bodegas Argentinas, (10), pp. 54-57.

Franco, J., Mehta, L., Veldwisch, G. (2013). The Global Politics of Water Grabbing. Third World Quarterly, 34(9), pp.1651-1675. https://doi.org/10.1080/01436597.2013.843852

Gorenstein, S., Ortiz, R. (2016). Las transnacionales agroalimentarias en América Latina y el Caribe: estrategias empresarias y marcos regulatorios globales. Revista Nueva Sociedad, (262), pp. 64-75.

Gras, C., Hernández, V. (eds.). (2009). La Argentina rural. De la agricultura familiar a los agronegocios. Buenos Aires, Argentina: Biblos.

Gras, C., Hernández, V. (eds.). (2013). El agro como negocio. Producción, sociedad y territorios en la globalización. Buenos Aires, Argentina: Biblos.

Harvey, D. (2007). Espacios del capital. Hacia una geografía crítica. Madrid, España: Akal.

Hoogesteger, J., Wester, P. (2015). Intensive Groundwater Use and (in)Equity: Processes and Governance Challenges. Environmental Science \& Policy, (51), pp. 117-124. https://doi.org/10.1016/j.envsci.2015.04.004

INV. (2017). Regiones vitivinícolas argentinas. Provincia Mendoza, Zona Valle de Uco (Tupungato, Tunuyán, San Carlos). Mendoza: Instituto Nacional de Vitivinicultura.

ISPAG. (2019). Home | International Society of Precision Agriculture. Recuperado de https://www.ispag.org/

La Nación. (2011, 14 de mayo). Mendoza, tierra del vino... y de la papa también. La Nación. Recuperado de http://www.lanacion.com.ar/1372921-mendoza-tierra-del-vino-y-de-la-papatambien

Lavie E., Marshall A. (eds.). (2017). Oases and Globalization: Ruptures and Continuities. Cham, Suiza: Springer International. https://doi.org/10.1007/978-3-319-50749-1

Larsimont, R. (2016). Hacia una ecología política de los negocios agro-turísticos en Mendoza, Argentina. Revista de Ecología Política. Cuadernos de debate internacional, (52), pp. 74-77.

Larsimont, R. (2018). Modelo de Agronegocio, Agua y Ruralidad en los Oasis de Mendoza, 19902017: hacía una Ecología Política Territorial [tesis de doctorado]. Buenos Aires, Argentina: Universidad de Buenos Aires.

Larsimont, R., Carballo, O., Ivars, J. (2018). Las papas de la globalización: el complejo agroindustrial papero en el Valle de Uco, Mendoza, Argentina. RIVAR, 13(5), pp.182-199.

Loyola, L. (2015). Evolución del riego en Argentina y perspectivas de futuro. Hydría, (54), pp. 50-56.

Lefebvre, H. (1973). Les idéologies de la croissance. L'Homme et la société, (27), pp. 3-17. https://doi.org/10.3406/homso.1973.1783

Lefebvre, H. (2014). La producción del espacio. Madrid, España: Capitán Swing.

Malizia, G. (2010, 4 de abril). Viticultura de precisión. Eficacia en la clasificación de viñedos. Área del Vino. Recuperado de http://www.areadelvino.com/articulo.php?num=20467 
Manoni, G. (2011, 27 de mayo). Del Valle de Uco salen las papas que ofrecen Mc Donald's y Burguer King. Los Andes. Recuperado de http://www.losandes.com.ar/article/valle-salen-papasofrecen-donalds-burguer-king-570902

Manoni, G. (2013, 26 de mayo). Pagan U\$S 60 mil por pozos de agua en el Valle de Uco. Los Andes. Recuperado de http://losandes.com.ar/article/pagan-pozos-agua-valle-716740

Margulis, M., McKeon, N., Borras, S. M. (eds.). (2014). Land Grabbing and Global Governance. Nueva York, NY: Routledge.

Martin, F. (2010). La naturaleza del poder. Ecología política del desarrollo (capitalista) regional en Mendoza, Argentina. 1879-2000 [tesis de doctorado]. Buenos Aires, Argentina: Universidad de Buenos Aires.

Martin, F., Larsimont, R. (2016). Agua, poder y desigualdad socioespacial. Un nuevo ciclo hidrosocial en Mendoza, Argentina (1990-2015). En G. Merlinsky (ed.), Cartografía del conflicto ambiental en Argentina II (pp. 31-56). Buenos Aires, Argentina: CICCUS-CLACSO. https://doi.org/10.2307/j.ctvt6rkxj.5

Marx, K. (1963). Critique de l'Économie politique [originalmente publicado en 1859]. En N. Guterman, H. Lefebvre (eds.), Karl Marx. Oeuvres choisies : Vol 1. París, Francia: Gallimard.

Marzo, M., Inchauspe, O. (1967). Geografía de Mendoza. Tomo I. Mendoza, Argentina: Mendoza Spadoni.

Mateu, M. (2007), El modelo centenario de la vitivinicultura mendocina: Génesis, desarrollo y crisis (1870-1980). En M. Delfini, D. Dubbini, M. Lugones I. Rivero (eds.), Innovación y empleo en tramas productivas de Argentina (pp.19-42). Buenos Aires, Argentina: UNGS-Prometeo.

McMichael, P. (2012). The land grab and corporate food regime restructuring. Journal of Peasant Studies 39(3-4), pp.681-702. https://doi.org/10.1080/03066150.2012.661369

Mehta, L., Veldwisch G. J., Franco, J. (2012). Introduction to the Special Issue: Water grabbing? Focus on the (re)appropriation of finite water resources. Water Alternatives 5(2), pp. 193-207.

Molle, F., Mollinga, P. P., Wester, P. (2009). Hydraulic bureaucracies and the hydraulic mission: Flows of water, flows of power. Water Alternatives, 2(3), pp. 328-349.

Montaña, E. (2012). Escenarios de cambio ambiental global, escenarios de pobreza rural: una mirada desde el territorio. Buenos Aires, Argentina: Colección CLACSO-CROP.

Navarría, A. (1999, diciembre). Fruta fresca mendocina para la contraestación de Europa. Revista de la Bolsa, (425), pp. 15-17.

Oré, T., Muñoz, I. (eds.). (2018). Aguas en disputa. Ica y Huancavelica, entre el entrampamiento y el diálogo. Lima, Perú: Fondo Editorial de la Pontificia Universidad Católica del Perú.

Peet, R., Watts, M. (eds.). (1996). Liberation Ecologies: Environment, Development, Social Movements. Londres, Reino Unido: Routledge.

Porolli, J. M. (2017, 4 de febrero). Esperan nuevas inversiones en riego por goteo para 2017. Los Andes. Recuperado de www.losandes.com.ar/article/esperan-nuevas-inversiones-en-riegopor-goteo-para-2017

Ratier, H. (2013). ¿Nuevas Ruralidades? Aproximaciones conceptuales a una categoría recurrente en los modernos estudios sociales sobre el campo. En H. Ratier, R. Ringuelet, J. Soncini (eds.), El Mundo Rural: Debates en torno a los nuevos procesos de configuración y reconfiguración en el siglo XXI (pp. 1583-1591). Santa Rosa, Argentina: Universidad Nacional de La Pampa. 
Robbins. P., Hintz, J., Moore, A. (2010). Environment and Society. Critical introduction to Geography. Singapur: Wiley-Blackwell.

Roncelli, I. (1969). Expansión actual del oasis de Tupungato: La conquista del suelo en zona baja. Boletín de Estudios Geográficos, 16(63), pp. 67-103.

Saldi, L., Scherbosky, R. (2018). Construcción de la memoria colectiva frente a la mercantilización de tierras cordilleranas. La experiencia de Campo Los Andes (Mendoza, Argentina). Eutopía. Revista de Desarrollo Económico Territorial, (14), pp. 155-174

Santos, M. (2000). La naturaleza del espacio. Técnica y Tiempo. Razón y Emoción. Madrid, España: Ariel.

Smith, N. (1984). Uneven Development: Nature, Capital, and the Production of Space. Oxford, Reino Unido: Blackwell.

Torres, L., Pastor, G., Grosso, V., Scoones, A. (2018). Turismo de lujo y extractivismo: la ruralidad como presa del capital. Reflexiones a propósito de Valle de Uco (Mendoza, Argentina). Scripta Nova, 22(585). Recuperado de http://revistes.ub.edu/index.php/ScriptaNova/article/view/19210/23382

TotalMedios. (2015, 10 de noviembre). Niña presentó su campaña gráfica “ayer y hoy” para Bodegas Salentein. TotalMedios. Recuperado de http://www.totalmedios.com/nota/26650/ninapresento-su-campana-grafica-ayer-y-hoy-para-bodegas-salentein

Tupungato Winelands. (2009). Winelands - Productivo - Tupungato Winelands. Recuperado de https://tupungatowinelands.com/winelands-productivo/

Van der Ploeg, J. D. (2008). The new peasantries: struggles for autonomy and sustainability in an era of empire and globalization. Londres, Reino Unido: Earthscan.

Vinífera. (1996). Vinífera: Revista del Instituto Nacional de Vitivinicultura, (2), pp. 35-40.

White, B., Borras, S. M., Hall, R., Scoones, I., Wolford, W. (2012). The new enclosures: Critical perspectives on corporate land deals. The Journal of Peasant Studies, 39(3-4), pp. 619-647. https://doi.org/10.1080/03066150.2012.691879

Yanke, R. (2018, 21 de agosto). Michel Rolland, la mejor nariz del mundo: "El mejor vino es el que más te gusta". El Mundo. Recuperado de https://www.elmundo.es/papel/historias/2018/08/21/5b76ae66e5fdea475c8b4571.html

Zoomers. A. (2010). Globalisation and the foreignisation of space: seven processes driving the current global land grab. Journal of Peasant Studies, 37(2), pp. 429-447. https://doi.org/10.1080/03066151003595325

\section{Entrevistados}

$\mathrm{N}^{\circ} 1$ Investigador en Riego y Drenaje del Instituto Nacional del Agua-CRA Mendoza. Noviembre de 2016.

N² Enólogo Bodega Valle de Uco. Gualtallary. Mayo de 2016.

N³ Winemaker y ex-enólogo jubilado de varias bodegas Tunuyán. Abril de 2016.

N 4 Ingeniero agrónomo de dos empresas de capitales extranjeros. Tupungato. Marzo de 2016.

N5 Ingeniero agrónomo Trivento (Concha y Toro), Tupungato. Septiembre de 2016. 
№6 Ingeniero agrónomo y técnico de riego de San Fili, San Carlos. Febrero de 2015.

N7 Ingeniero agrónomo holandés de Farm Frites, Tunuyán. Junio 2014.

N8 Ingeniera agrónomo de Farm Frites, Tunuyán. Junio de 2014.

$\mathrm{N}^{\circ} 9$ Poblador del distrito de Gualtallary, Tupungato. Febrero de 2016.

$\mathrm{N}^{\circ} 10$ Pobladora del distrito de Gualtallary, Tupungato. Febrero de 2016.

№11 Hidrogeólogo del Departamento General de Irrigación. Departamento de Aguas Subterráneas (Subdelegación del Tunuyán Superior), San Carlos. Febrero de 2016.

$\mathrm{N}^{\circ} 12$ Dueña Finca La Azul, Tupungato. Septiembre de 2016 (entrevista realizada por integrantes del grupo Ciudad y Territorio de CONICET Mendoza).

№13 Secretario de Gestión Hídrica del Departamento General de Irrigación. Octubre de 2016.

N¹4 Pequeño Productor de durazno, Villa Seca. Septiembre de 2016.

N¹5 Ingeniera agrónoma de una gran bodega de capitales nacionales, San Carlos. Febrero de 2016.

№16 Ex-productor frutícola, Gualtallary. Noviembre de 2016. 